\title{
ESTEREOTIPOS Y ROLES SOCIALES DE LA MUJER EN EL CINE DE GÉNERO DEPORTIVO.
}

Resumen: Este documento profundiza en el rol y cualidades asociadas a la mujer en el cine deportivo de la primera década del siglo XXI, objeto de estudio poco habitual en el segmento de la investigación cinematográfica. Para ello, se determinó una muestra compuesta por 74 películas, seleccionadas a través de un muestreo no probabilístico por cuotas y mediante un diseño de investigación de tipo descriptivo, siendo el análisis de contenido el instrumento elegido para llevarlo a cabo. Los resultados arrojaron que se reflejaba con fidelidad el modelo imperante en la actualidad, así como el canon moderno que se atribuye al sexo femenino, lo cual debería cuestionar el peso que supone la industria cinematográfica como instrumento de normalización en el tratamiento de la mujer.

Palabras clave: Deporte; cine; mujeres; roles de género.

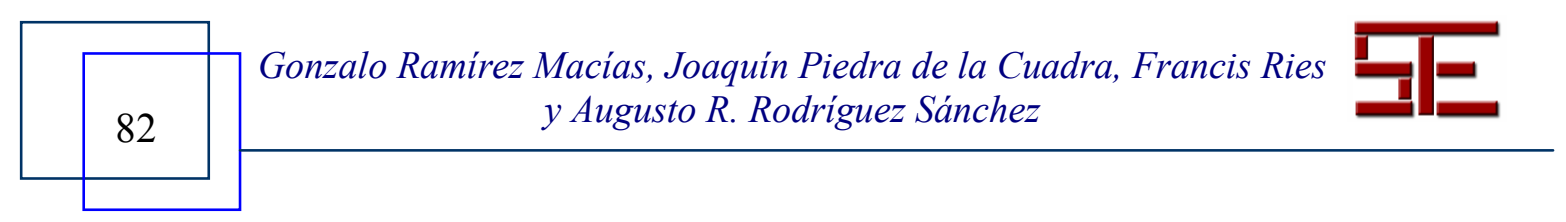




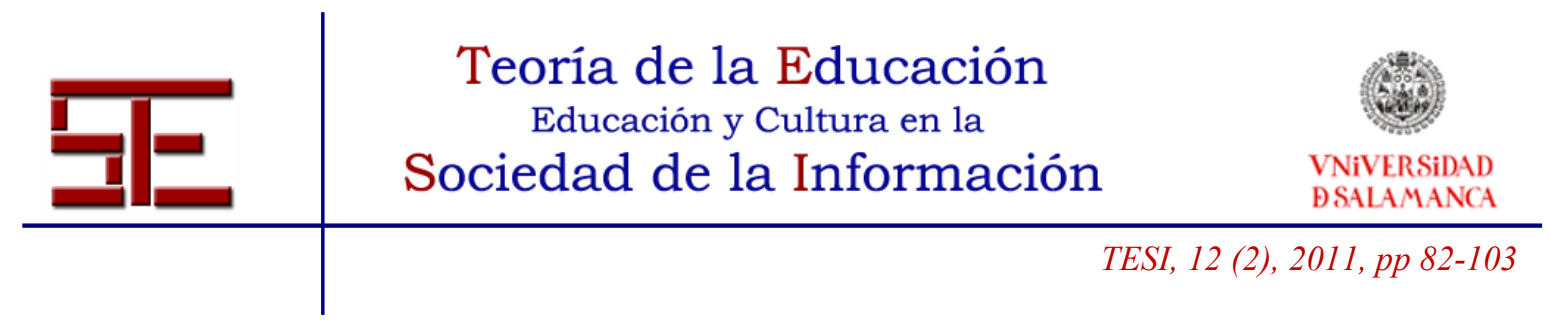

\section{STEREOTYPES AND SOCIAL ROLE OF WOMEN IN SPORTS GENDER FILMS.}

Abstract: This paper explores the role and qualities associated to women in sports movies of the first decade of the $21^{\text {st }}$ century and it represents an unusual study in the segment of film research. To do this, we investigated a sample of 74 films, selected through a non-probability quota sampling and research design using a descriptive, content analysis as an instrument to carry it out. The results showed that the prevailing model of our society is faithfully reflected, and the same happens to the modern canon attributed to females, which should question the importance of the film industry as a means of correction in the treatment of women.

Keywords: Sports; cinema; women; sex roles.

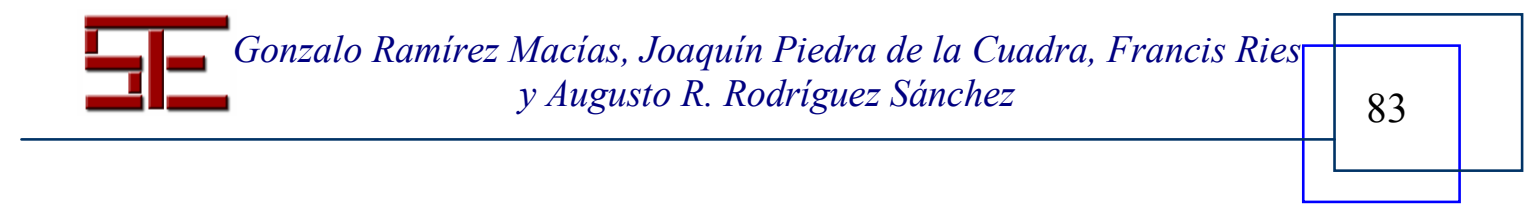




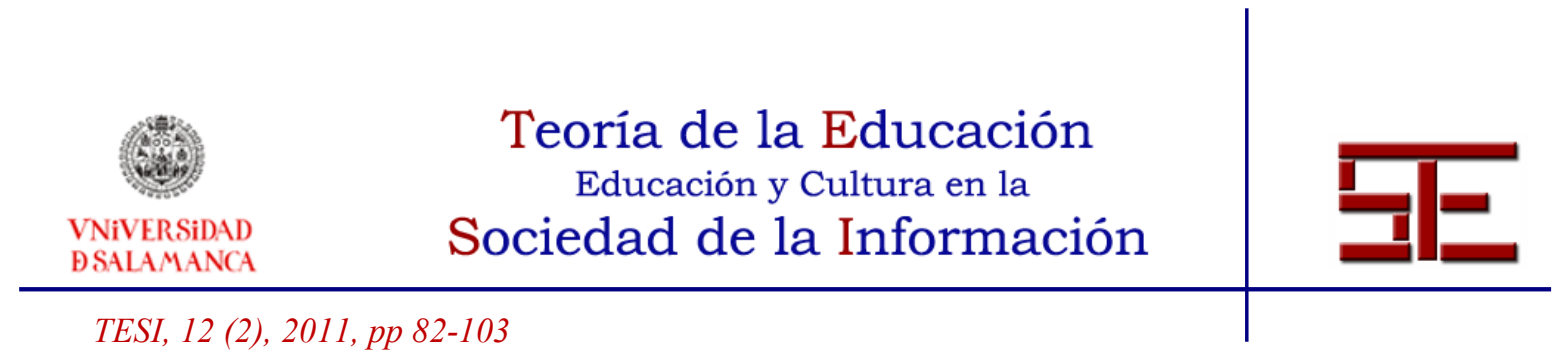

\title{
ESTEREOTIPOS Y ROLES SOCIALES DE LA MUJER EN EL CINE DE GÉNERO DEPORTIVO
}

Fecha de recepción: 15/04/2011; fecha de aceptación: 29/06/2011; fecha de publicación: 27/06/2011

\author{
Dr. Gonzalo Ramírez Macías \\ grm@us.es \\ Departamento de Educación Física y Deporte \\ Universidad de Sevilla \\ Dr. Joaquín Piedra de la Cuadra \\ jpiedra@us.es \\ Departamento de Educación Física y Deporte \\ Universidad de Sevilla \\ Dr. Francis Ries \\ fries@us.es \\ Departamento de Educación Física y Deporte \\ Universidad de Sevilla
}

Augusto R. Rodríguez Sánchez

rembrandt@us.es

Universidad de Sevilla

\section{1.- INTRODUCCIÓN.}

Los medios de comunicación son, en el más amplio sentido de la palabra, una parte importante de la sociedad de la información. Como afirma Loscertales (2007) nunca hasta este momento se había disfrutado de tal cantidad y calidad de medios (prensa, radio, televisión, Internet, etc.) e instrumentos tecnológicos, que nos acercan a cualquier lugar del planeta, nos informan, nos instruyen y nos entretienen. En definitiva, el gran desarrollo de los medios de comunicación, ha provocado que éstos hayan cobrado gran importancia en la socialización de las personas dentro de nuestra cultura global (Bandura, 1986).

En relación a la mujer, ya desde los inicios de los movimientos feministas en la segunda mitad del siglo XX, se vienen desarrollando en la comunidad científica estudios que abordan la problemática del tratamiento de la mujer en los medios de

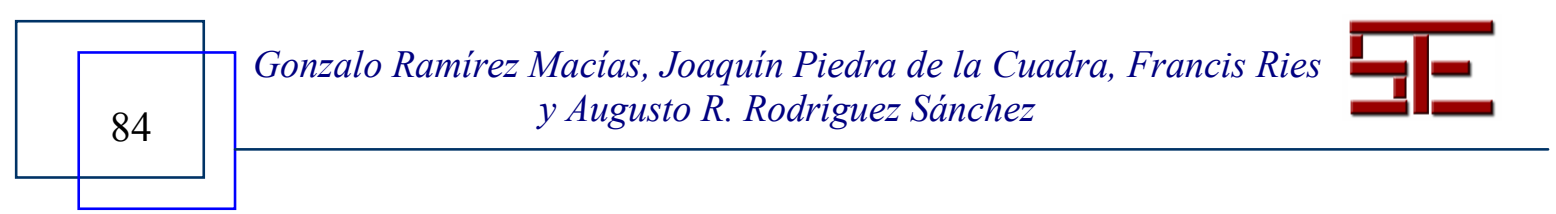




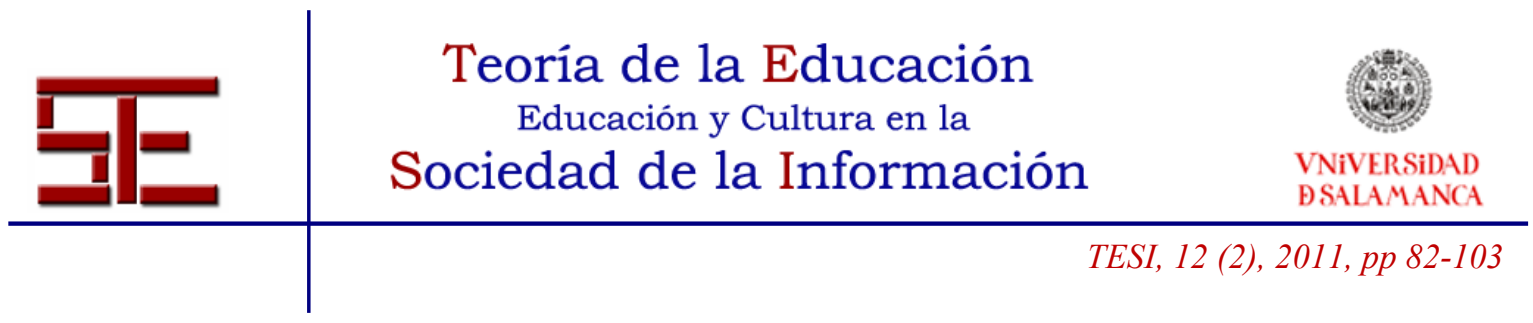

comunicación. Como afirman Blanco y Naranjo (2008) estos medios son elementos conformadores de la realidad social y tienen gran responsabilidad en la proyección de la imagen de la mujer.

Los estereotipos de género en los medios ha sido una de las áreas más estudiadas, demostrándose que la mujer continua siendo vista en la sociedad occidental de un modo estereotipadamente negativo, retratando una imagen irreal de la misma (Bishop, 2003; King, 2007; Rowe, 2004; Blanco y Naranjo, 2008).

Los mecanismos que suelen utilizarse en los medios de comunicación para incidir en esta visión estereotipada son variados, según Contreras (2007) dentro de éstos destacan: la trivialización de temas femeninos, la eliminación de éxitos que son reemplazados por detalles de la apariencia personal (indumentaria, maquillaje, etc.), la transformación de la mujer en un objeto sexual, la reducción del espacio vital femenino circunscribiéndolo a la familia y la presentación de la mujer como un ser débil que es víctima de violencia.

En relación a esta visión estereotipada de la mujer, tiene especial interés el ámbito de la belleza femenina, en el que se le perpetúa como un individuo escultural, muy delgado, con pocas caderas y extremadamente atractivo, características que sólo corresponden con el 5\% de la población total de mujeres adultas (Neuendorf, Gore, Dalessandro, Janstova y Snyder-Suhy, 2010). Por todo ello, en relación al discurso patriarcal y tal como afirma Contreras (2007), los medios respaldan las estructuras sociales dominantes, las reproducen y mantienen, participando en el proceso de formación social.

Según Loscertales (2007), los medios de comunicación más importantes son aquellos en los que prima lo icónico (imágenes, luces, colores, etc.) todo ello combinado con lo verbal, pero sin ceder a la palabra más que el espacio mínimo imprescindible. En este gran grupo de medios audiovisuales se halla en primer lugar la televisión junto a sus productos de ficción fundamentales, concretamente el cine y, con él, las series televisadas. Después estarían Internet, los móviles y los videojuegos.

Así pues, el cine aparece como un elemento importante del ocio colectivo, que al igual que otros medios audiovisuales ha proliferado en los últimos decenios gracias a las Tecnologías de la Información y la Comunicación (TICs). Al respecto hay que destacar, como afirma Stromquist (2009), que las TICs configuran densas y veloces formas de

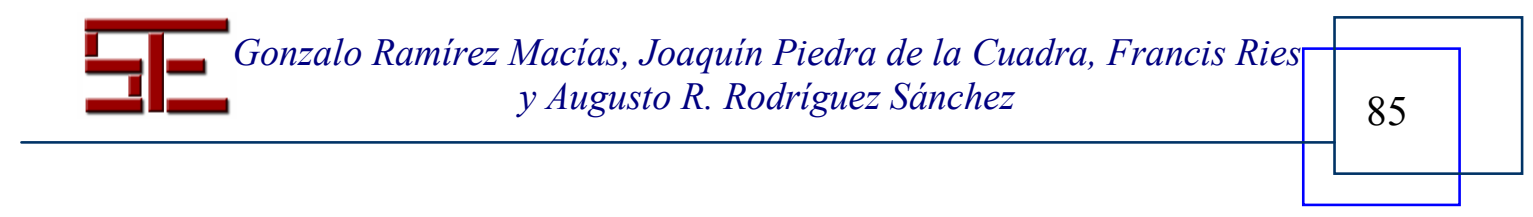




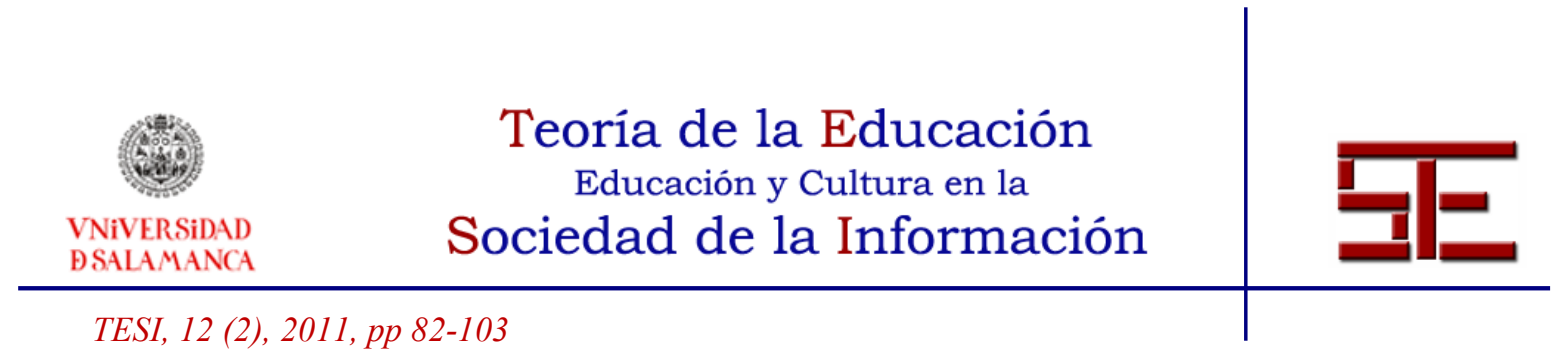

transmisión de ideas que no se hallan libres de valores sino que tienen efectos sobre la sociedad y éstos, en relación a la mujer, son generalmente adversos.

En la actualidad se puede consumir cine en formatos muy variados: televisión portátil, ordenador portátil, Televisión Digital Terrestre (que ha aumentado sobremanera el número de canales televisivos), videoclubes digitales, Internet (incluyendo los portales de descargas cinematográficas), salas de cine, etc. Todo ello ha aumentado no sólo la producción de películas sino el consumo de éstas como producto de ocio.

Por tanto, es posible afirmar que, en la sociedad de la información en la que vivimos, todo aquello que se produce en el cine se exporta, mucho más que hace 50 años, al resto del mundo; por ello, las grandes productoras cinematográficas tienen su papel en la construcción de la sociedad. Los roles que hombres y mujeres desempeñan en sus historias son observados y en muchos casos asumidos como normal por los espectadores. En este punto es preciso subrayar la opinión de Guarinos (2007), autora que afirma que de todos los medios de comunicación el cine es sin duda el pionero en la absorción y proyección de elementos para la realimentación de la sociedad de la que procede y a la que sirve. Por tanto, es pionero en la reproducción y transmisión del discurso patriarcal que asigna determinados estereotipos y roles a la mujer.

Dentro de los diferentes géneros cinematográficos, en relación a dichos estereotipos y roles, tienen un interés especial las películas de género deportivo, entendiendo a éste como aquel en el que el argumento gira en torno a una o varias actividades deportivas. La afirmación anterior se sustenta en el hecho de que el deporte es una realidad social especialmente proclive al discurso patriarcal dentro de los medios de comunicación, como demuestran varios estudios precedentes (González, 2005; López, 2005; Guarinos, 2007; Ramírez, en prensa).

En base a la argumentación expuesta, se planteó realizar este estudio cuya finalidad es investigar los personajes femeninos de las películas de género deportivo de la primera década del siglo XXI, valorando si reproducen los estereotipos y roles sociales que se imponen en la sociedad occidental con respecto al género femenino.

En la definición hecha sobre la finalidad del estudio, es preciso concretar dos elementos esenciales de la misma. En primer lugar el concepto de estereotipo, entendido como "una imagen convencional, acuñada, un prejuicio o creencia popular sobre grupos de gente; que los categoriza según su aspecto, conducta o costumbres" (Correa, Guzmán

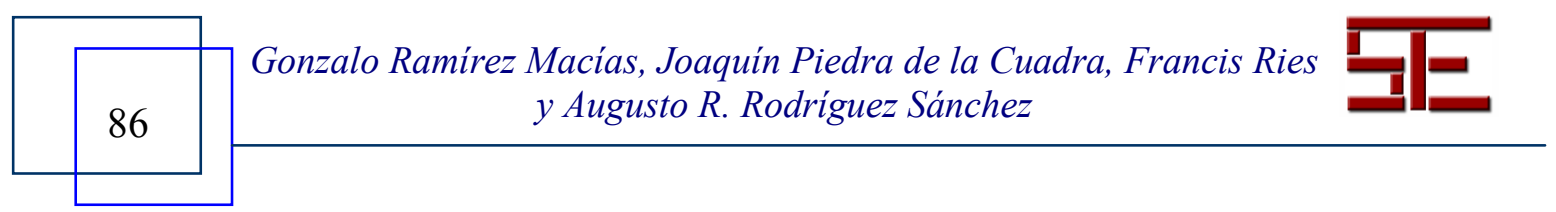




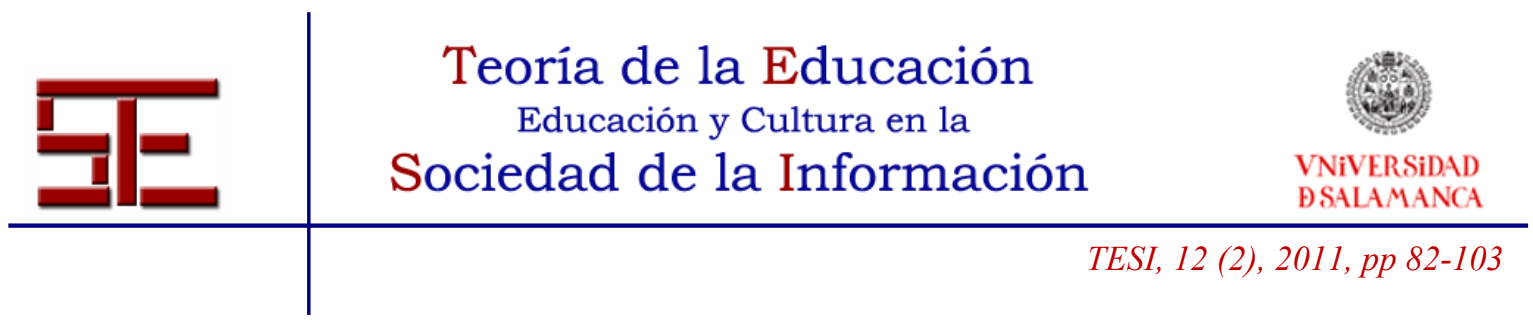

y Aguaded, 2000). En segundo lugar el concepto de estereotipo sexista, definido como el sistemas de creencias acerca de los grupos de hombres y mujeres en general o sobre las características de masculinidad y feminidad por ellos desarrolladas (Barberá, 2004).

\section{2.- REVISIÓN DE LA LITERATURA.}

La introducción de la mujer y otras minorías en el cine moderno del pasado siglo, es un indicativo del impacto tanto de los derechos civiles como de los movimientos feministas. Según Pearson, Curtis, Haney y Zhang (2003), en el ámbito norteamericano, la ley Title IX de prohibición de discriminaciones en función del sexo en instituciones que perciban ayuda estatal, ha conducido un incremento en películas deportivas con protagonistas femeninos. Sin embargo, las películas de Hollywood sobre deporte generalmente se centran en el cuerpo masculino (Cook, 1982 citado por Guttman, 1996).

La década de los 60 ha producido grandes adelantos en la igualdad de mujeres y hombres, así como una mayor representación femenina en el deporte. La conciencia social y la democratización prominente en la década de los 70 , ha destacado en sátiras y exposiciones, así como películas que retratan prácticas antiheróicas y no éticas en el deporte (Pearson et al., 2003).

Como afirma Kuhn (1982, citado por Duncan y Hasbrook, 2002), las películas tienen con frecuencia una función de represión de la feminidad en las sociedades patriarcales. Según Neuendorf et al. (2010) y Huggins (2007) se pueden clasificar en tres los principales roles desempeñados por las mujeres en las tramas cinéfilas. Por un lado el de "heroína subversiva", entendiéndose por aquella mujer fuerte y valiente que transgrede los cánones femeninos y de la sociedad y que suele ser sexualmente activa. Por otro lado la mujer "villana o femme fatal", sería aquella mujer fuerte, en ocasiones manipuladora y corruptora, que puede tener a su mando a un hombre y que es activa sexualmente. Por último la denominada por Clemente (2007) "Cenicienta", que sería la mujer bondadosa y tierna, que cuida de los demás y que normalmente necesita la ayuda de su amado, suele ser pasiva y "pura" sexualmente. Sin embargo, estas características de autonomía que tienen alguno de estos roles, no la sitúan como tal, sino adjunta al protagonista.

Siguiendo a Gilpatric (2010) y Guttman (1996) los estereotipos asignados a hombres y mujeres en el cine son, para los primeros: dominantes, agresivos,

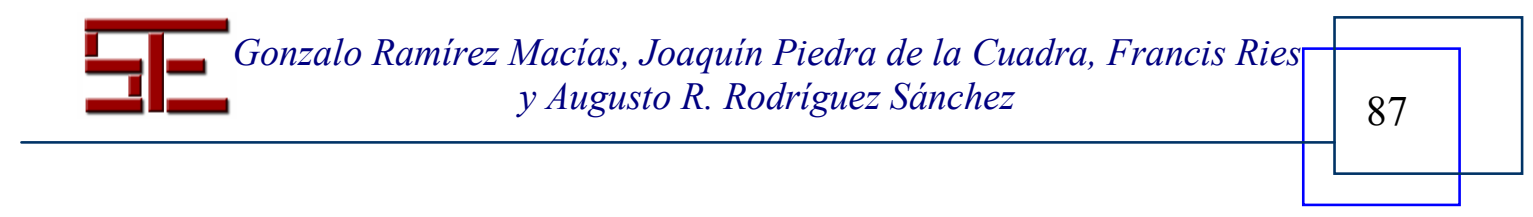




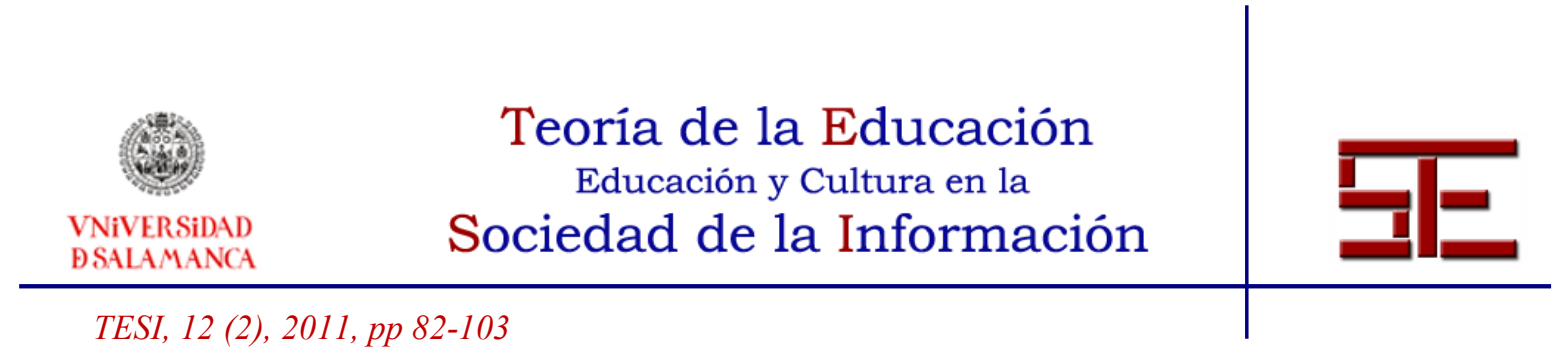

competitivos, hipermusculados, independientes, ambiciosos, decididos y aventurados; para las segundas: afectivas, sumisas, emocionales, simpáticas, gentiles $\mathrm{y}$ comunicativas.

También la imagen corporal juega un papel importante en la construcción del yo de las personas (Garrett, 2004), sobre todo en el caso de las mujeres. Por ello, la imagen no realista del cuerpo femenino que se ofrece en las películas puede llevar a algunas mujeres desviaciones en su identidad e incluso a enfermedades como la anorexia o la bulimia.

En su análisis de género dentro de las películas deportivas del cine americano, Baker (2006) afirma que las mujeres, salvo en contadas ocasiones, son representadas con papeles de débiles animadoras y jugadoras de deportes de equipo. En la mayoría de las películas en la que la mujer practica un deporte trasgrediendo los cánones heteronormativos de la sociedad patriarcal, el final de la historia se presenta cuando ésta abandona la carrera deportiva y se casa con el amado, volviendo así, al lógico equilibrio patriarcal de la sociedad americana. En muchas de estas películas se muestra el miedo de las mujeres deportistas de ser vistas como mujeres masculinizadas, miedo que se produce por la no aceptación en la cultura occidental de diferentes rasgos que se aparten del binomio clásico masculino-femenino.

En los últimos años han sido rodadas diversas películas deportivas cuya trama central la desarrolla un personaje femenino (Boyle, Millington y Vertinsky, 2006; Caudwell, 2008). Sobre una de ellas (Girlfight, 2000), la investigadora británica Caudwell (2008) afirma que la actividad y el cuerpo físico de la protagonista pueden ser leídos como transgresivos. Como afirman Pearson et al. (2003), las condiciones sociales existentes a finales del siglo XX y principios del siglo XXI tienen su impacto sobre la sociedad occidental y en su representación en el cine, especialmente en el cine deportivo. Dichas películas producen un cierto tipo de imágenes e historias de las mujeres. Estas representaciones definen pocas posibilidades de feminidad de la mujer e incluyen una versión particular de la sexualidad femenina (Caudwell, 2008).

Históricamente, el deporte ha sido una práctica excluyente en una doble vertiente, por un lado era propio de la elite social y, por otro lado, era practicado exclusivamente por hombres (Salvador, 2004). Por tanto, es posible afirmar que el deporte ha sido y es origen de estereotipos sexistas hacia las mujeres.

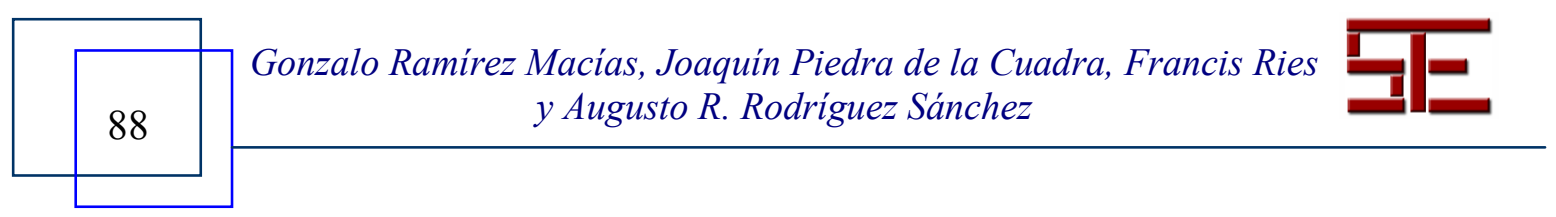




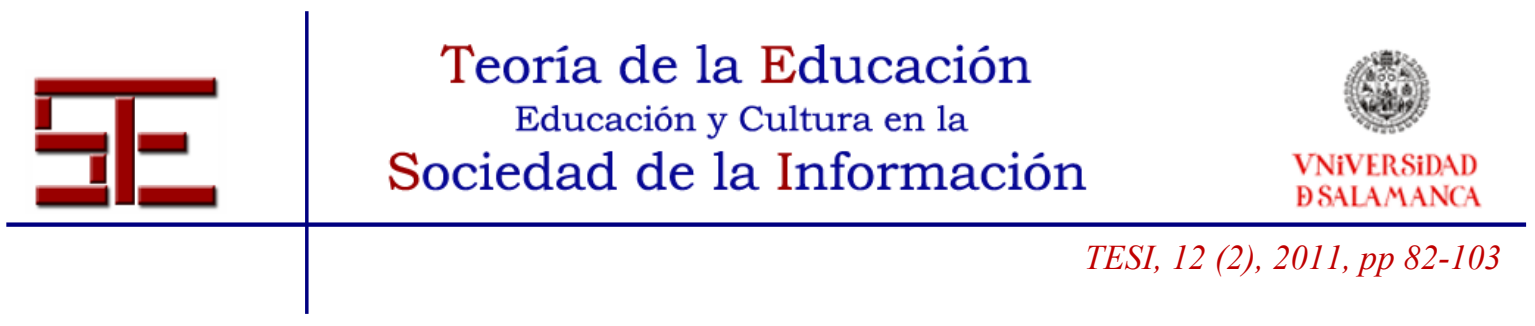

En la actualidad, afortunadamente, se ha logrado que las mujeres tomen parte, sin ser consideradas varoniles, en los deportes típicamente masculinos tales como el boxeo, la lucha el fútbol, el triatlón, etc. Los niveles de práctica deportiva femenina han subido en gran medida en las últimas décadas llegando a niveles casi parejos al de los hombres, e incluso superándolos en algunos casos. Sin embargo, en el deporte de ocio, los intereses de mujeres y hombres se mueven en direcciones diferentes. Las mujeres tienen motivos más relacionados con la salud y la estética, mientras que los hombres lo hacen más por diversión y competitividad (Pfister, 2010). Además, también es de resaltar que mientras que las mujeres toman parte en deportes masculinos, no sucede lo mismo con la participación de los hombres en los deportes más femeninos.

De igual modo, también se ha producido un aumento general en el número de programas, películas y retrasmisiones que contienen imágenes estéticamente agradables dirigidas a un público femenino. Tanto para los medios de comunicación como para los consumidores masculinos del deporte, las atletas femeninas que irradian un aura de erotismo en los deportes masculinos parecen tener una atracción especial. Por ello, hoy se considera a las mujeres futbolistas particularmente atractivas e incluso sexys (Pfister, 2010). La objetivización y erotización del cuerpo femenino con finalidades comerciales es muy clara en el deporte (Messner, 2002). Muchas atletas transforman sus indumentarias convirtiéndolas en puros objetos del deseo y mostrando así un mensaje ambiguo, las deportistas son mujeres sensuales (Hargreaves, 1994).

Según Messner (2002), las mujeres deportistas sufren cuatro formas de discriminación por los medios de comunicación que pueden ser aplicadas al cine de género deportivo:

- Silence, no existe presencia, o muy poca, de mujeres en este tipo de películas.

- Humorous Sexualization, se muestran prácticas y actividades no serias del deporte femenino para darle un cariz no serio y una sexualización del cuerpo femenino.

- Backlash against women's sports, resaltando con posturas misóginas y homofóbicas aspectos o actuaciones de la mujer de manera negativa.

- Selective incorporation of standout women athletes, utilizar los personajes femeninos para intereses políticos o sociales.

Por todo ello, podemos concluir que las mujeres, dentro del deporte, tienen que equilibrar sus habilidades deportivas con feminidad para poder ser aceptadas (Huggins,

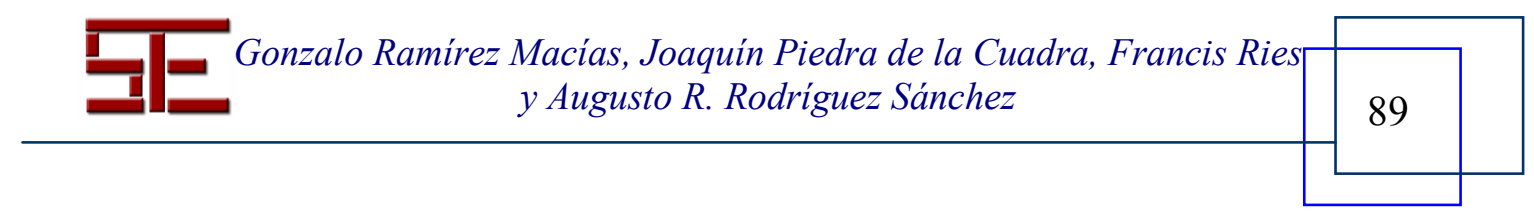




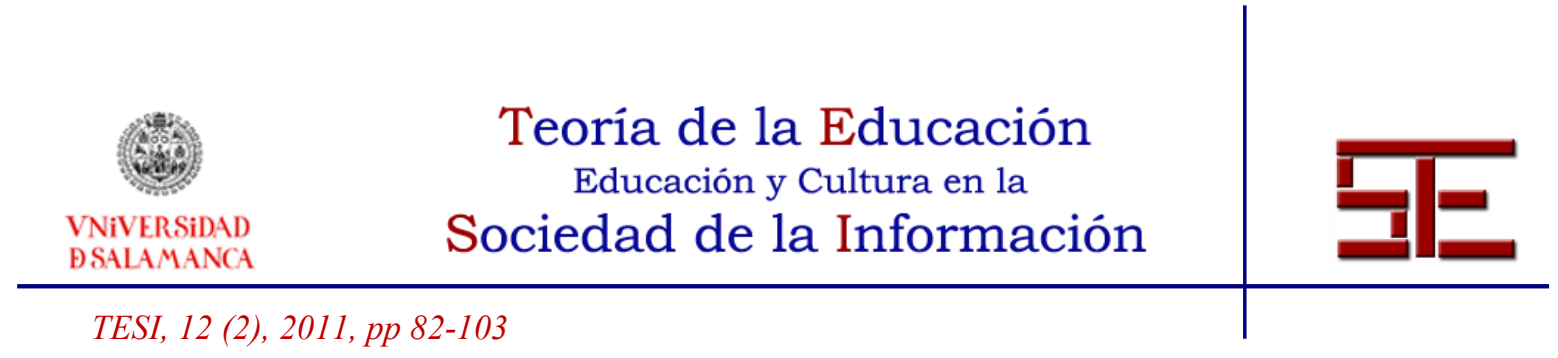

2007), si no rápidamente son calificadas como poco femeninas, ya que se alejan de su estereotipo y se acercan a los masculinos. El legado histórico junto con las férreas asunciones actuales de "sentido común" se traducen en la institucionalización de normas, prioridades y prácticas específicas para cada género (Scraton, 1992). Dichas prácticas y normas de género en el deporte, siguiendo a Schneider (2000), a Blández, Fernández y Sierra (2007) y a Crawford y Unger (2004), son para la mujer: ritmo, expresión, elasticidad, flexibilidad, belleza.

\section{3.- MÉTODO}

Siguiendo el criterio "manipulación de variables y objetivos de investigación" definido por Bisquerra (1989), esta investigación pertenece a las de tipo descriptivo, ya que no manipula ninguna variable sólo se dedica a describir fenómenos propios de la sociedad actual.

La población de esta investigación queda conformada por las películas de temática deportiva filmadas entre los años 2000 y 2009, entendiendo esta temática como aquella en el que el argumento gira en torno a una o varias actividades deportivas; debido a la gran cantidad de películas que cumplían estos criterios fue necesario la selección de una muestra, entendiéndola como un subconjunto representativo de la población original. La selección de la muestra se realiza en mayor parte de entre aquellas películas que por su gran distribución y difusión en Europa y Estados Unidos son de fácil acceso, dejando fuera de la muestra a un buen número de largometrajes de origen asiático, latinoamericano o africano de escasa comercialización y repercusión en la sociedad occidental en la que nos encontramos.

La muestra queda finalmente conformada por 74 películas, las cuales son seleccionadas por el método de muestreo no probabilístico por cuotas (Bogdan, 2007). En este método se fija una cuota, que consiste en un número de sujetos que reúnen unas determinadas características, en el caso de esta investigación 74 películas que cumplen la condición de que su argumento gira en torno a una o varias actividades deportivas.

Se toma como referencia para la selección de la muestra los rankings de Box Office Mojo ${ }^{10}$, de FilmAffinity ${ }^{11}$ y de IMDb (Internet Movie Database) ${ }^{12}$. El primero es un sitio web que brinda información sobre cine; comienza en 1998 y actualmente recibe más de un millón de visitantes mensuales. El segundo es un sitio web creado en 2002, done se evalúan, comentan y recomiendan películas cinematográficas, con una extensa

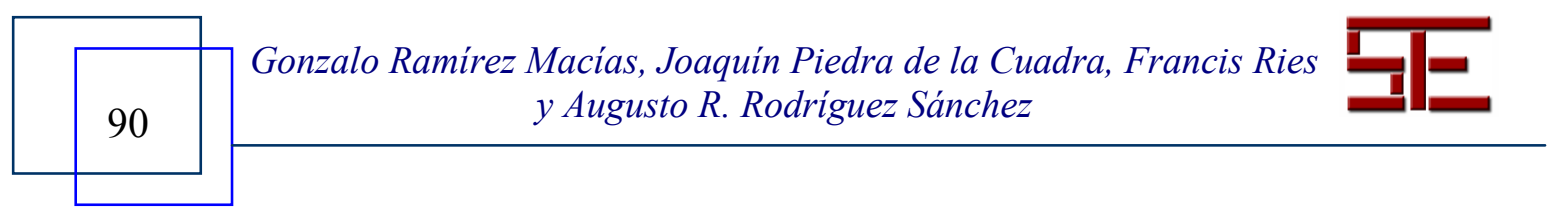




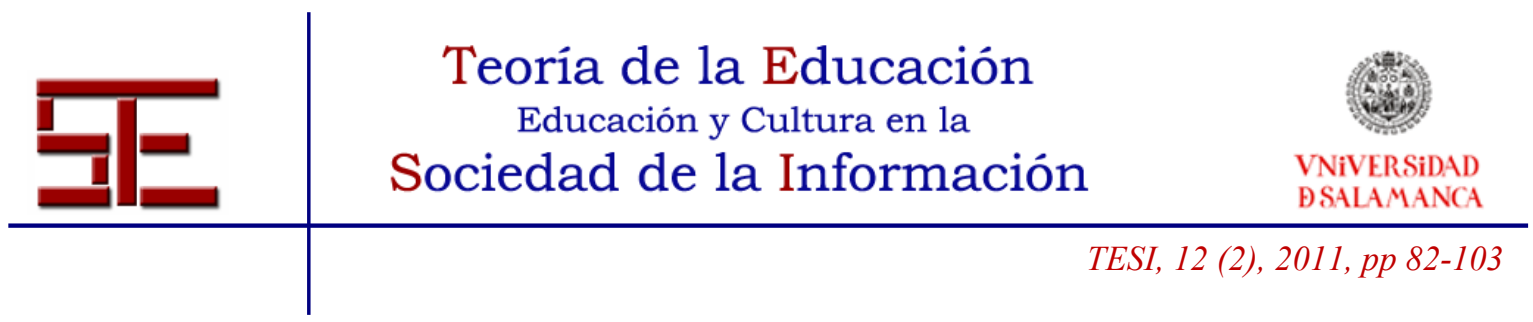

base de datos donde se encuentra la ficha completa (técnica y artística) de una gran cantidad de éstas, llegando en la actualidad a más de 40.000. Por último IMDb, inaugurada en 1990, es una base de datos en línea de información relacionada con películas, directores, productores, y actores y actrices que contiene una exhaustiva lista de películas, siendo el portal cinematográfico de referencia a nivel mundial.

Siguiendo a Bardin (1986), Krippendorff (1990) y Neuendorf (2002), el diseño de investigación queda definido en tres fases:

Preanálisis: A partir de una revisión bibliográfica en profundidad sobre estudios precedentes, se determina que la técnica de investigación que mejor se adapta a este estudio es el Análisis de Contenido, con objeto de obtener de forma metódica los datos contenidos en las fuentes que son de relevancia para esta investigación. Todo contenido de un texto o imagen puede ser interpretado de forma directa y manifiesta, o de una forma soterrada en su sentido latente e indirecto (que se sirve del manifiesto para expresar un sentido oculto).

Como afirma Neuendorf (2002), el Análisis de Contenido se utiliza para descodificar mensajes manifiestos y ocultos plasmados en diferentes tipos de medios: prensa, radio, televisión, películas..., pudiendo analizar diferentes tipos de signos: verbales y no verbales, icónicos-sonoros o icónicos-visuales.

En segundo lugar, se procede a definir las categorías descriptoras del objeto de investigación, a partir de dicho objeto y de las propuestas realizadas en estudios precedentes por Huggins (2007), Gilpatric (2010), Baker (2006), Pearson et al. (2003) y Caudwell (2008). Para esta definición se tuvieron presentes los modelos de desarrollo de categorías inductivas y deductivas de Mayring (2000). La formación del sistema categorial es la fase más significativa del Análisis de Contenido, ya que refleja directamente el propósito del investigador y la teoría subyacente que organiza el estudio.

En tercer lugar, la propuesta metodológica fue consultada a tres expertos, con objeto de que fuera valorada y corregida. A partir de las aportaciones de dichos expertos, el sistema de categorías descriptoras fue redefinido con mayor precisión.

En cuarto lugar, los investigadores se sometieron a un proceso de preparación como codificadores, conformado por dos fases:

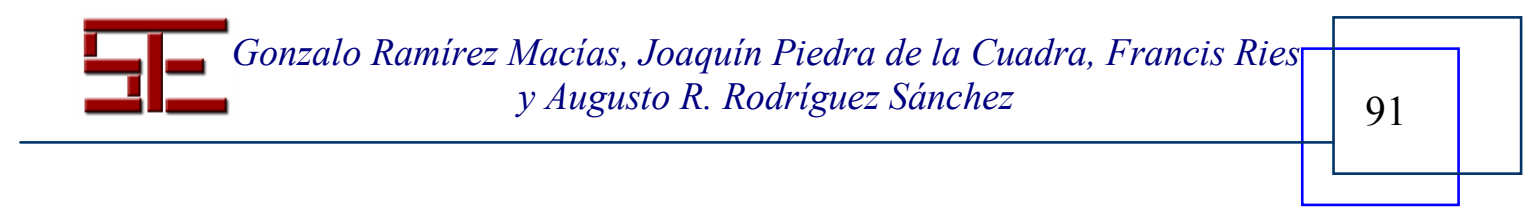




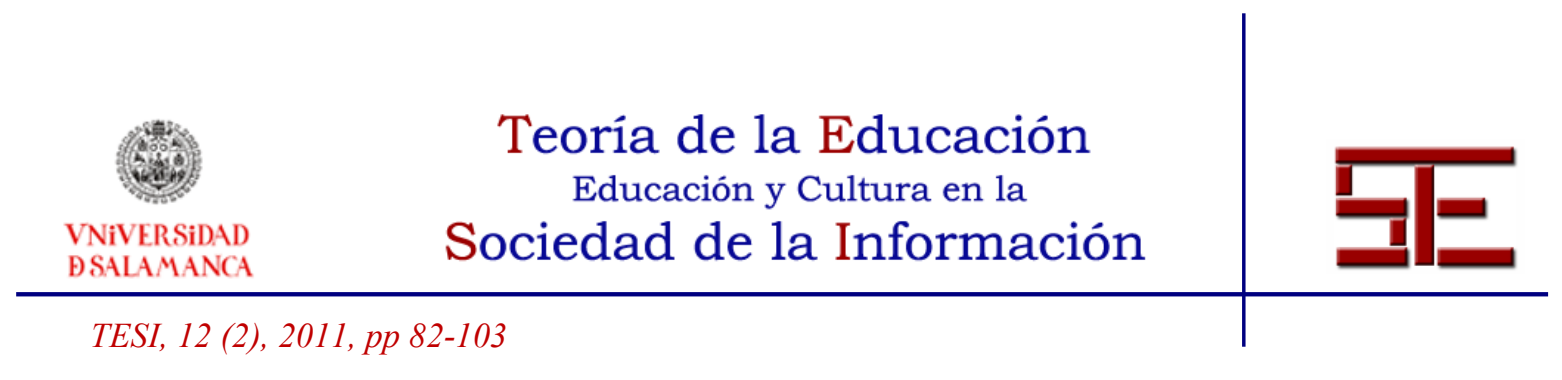

- Exposición de la técnica de investigación y de las categorías descriptoras, incidiendo en la comprensión de los ítems de la categorización.

- Entrenamiento a partir de la presentación y codificación individual de varias películas de género deportivo (10 películas) para posterior puesta en común de resultados. Este periodo de entrenamiento tenía como principal objetivo alcanzar la fiabilidad necesaria y se mantuvo hasta lograr de forma estable un índice de correlación mayor a 0.8 .

Una vez definida la técnica de investigación, las categorías descriptoras y codificadores y realizada la prueba piloto, las categorías descriptoras fueron redefinidas por segunda vez, clarificándose y puntualizándose ítems que en la práctica eran confusos. Finalmente, se realizó una nueva consulta a otros tres expertos en relación a la validez de la metodología propuesta, especialmente en relación al sistema de categorías descriptoras, aplicándose las modificaciones que dichos expertos sugirieron.

Codificación: A la muestra seleccionada se le aplicó la metodología de investigación definida en la fase anterior, de forma que cada uno de los investigadores codificó individualmente cada una de las películas de la muestra seleccionada. Posteriormente, y al igual que sucedió en la fase de preparación, los resultados de cada investigador fueron comparados con el resto; de esta forma se comprobó que existía un índice de correlación medio entre codificadores de 0.83 .

Análisis e interpretación: Una vez obtenidos los datos de la muestra, con objeto de profundizar en el significado de los mismos, se realizó un análisis descriptivo de frecuencias, con la finalidad de conocer y representar de forma clara y precisa estos datos.

\section{4.- RESULTADOS}

El análisis descriptivo de frecuencias arroja los siguientes resultados. En primer lugar se destaca el gran predominio de las producciones estadounidenses en lo que a películas de género deportivo se refiere, las cuales llegan a un 59,46\% que las destaca sobremanera de las situadas en segundo y tercer lugar, las europeas con un 17,57\% y las asiáticas con un $9,46 \%$. Al respecto es preciso subrayar el número, nada desdeñable, de

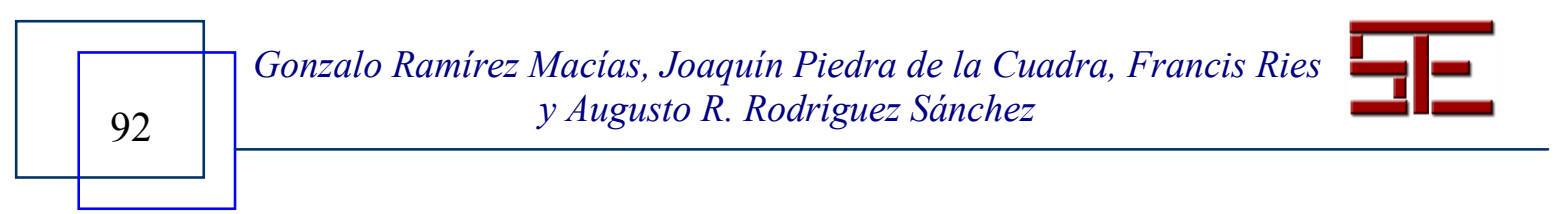




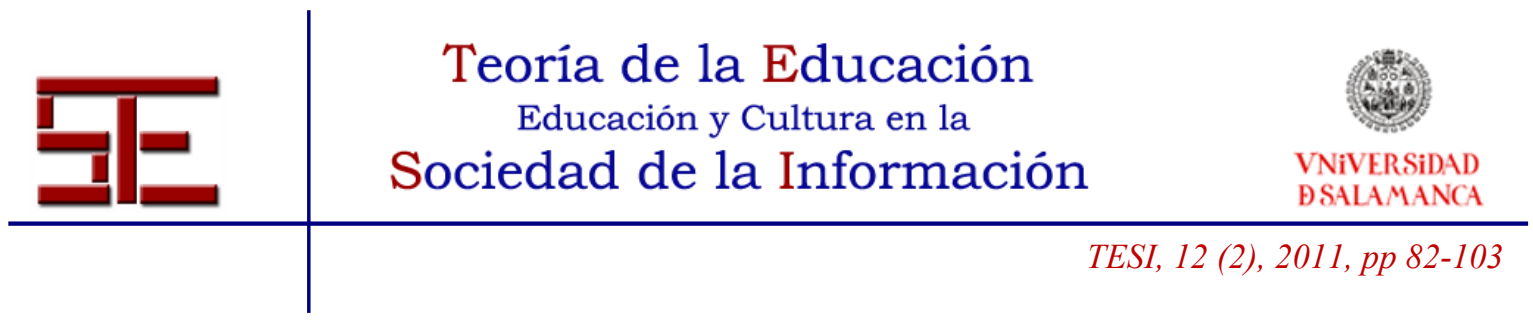

producciones mixtas que representan el 12,16\% (la mayoría de estas producciones tienen colaboración estadounidense).

El género de estos largometrajes gira en torno al drama en más de la mitad de los casos, siendo la acción y la comedia las siguientes temáticas, aunque a gran distancia. Este aspecto es reseñable porque de él se concluye que la mayoría de estas películas recurren al ámbito dramático del deporte: por ejemplo, son frecuentes las historias de equipos deportivos con grandes dificultades que acaban saliendo victoriosos gracias al trabajo y al esfuerzo colectivo.

Una categoría interesante de esta investigación es "ejercicio físico practicado por los personajes femeninos", ya que el hecho de representar la práctica de actividad física de las mujeres puede repercutir de manera indirecta en la promoción de dicha práctica. De la muestra, en 46 películas (un 72,16\% del total) aparece algún personaje femenino realizando algún tipo de actividad física, siendo la mitad de este valor prácticas asociadas tradicionalmente a las mujeres (danza, animadoras, fitness...). La otra mitad de los casos corresponden con actividades como los deportes de equipo, de motor, deportes de invierno u otras. De estas manifestaciones físico-deportivas llevadas a cabo por los personajes femeninos, se estima que un 58,06\% tienen una finalidad competitiva, mientras que el resto se realiza con fines lúdicos $(32,26 \%)$ o utilitarios $(9,68 \%)$.

Es muy destacable el desfase existente entre la categoría referida al ejercicio físico en torno al cual gira la película y las actividades practicadas por los personajes femeninos; en especial es llamativa la diferencia existente en el caso de los deportes de equipo (sobre éstos tratan un total de 32 películas y, sin embargo, sólo en 7 de ellas las féminas practican este tipo de deportes) y en el de los deportes de combate (sólo en 3 películas las mujeres practican actividades de este tipo, siendo el total de películas referidas a esta tipología 16 ).

En el polo contrario se hallan las películas que giran en torno a actividades coreográficas, sobre las que únicamente existe un único caso, que contrasta con el número de películas en el que las féminas practican actividades de esta índole, un total de 10 .

En relación a los personajes, se ha registrado la aparición de 830 protagonistas en la muestra (principales y secundarios), de los 263 son femeninos $(31,68 \%)$.

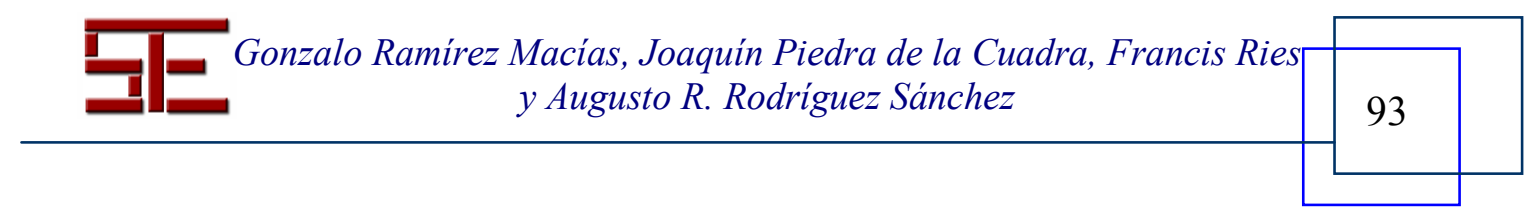




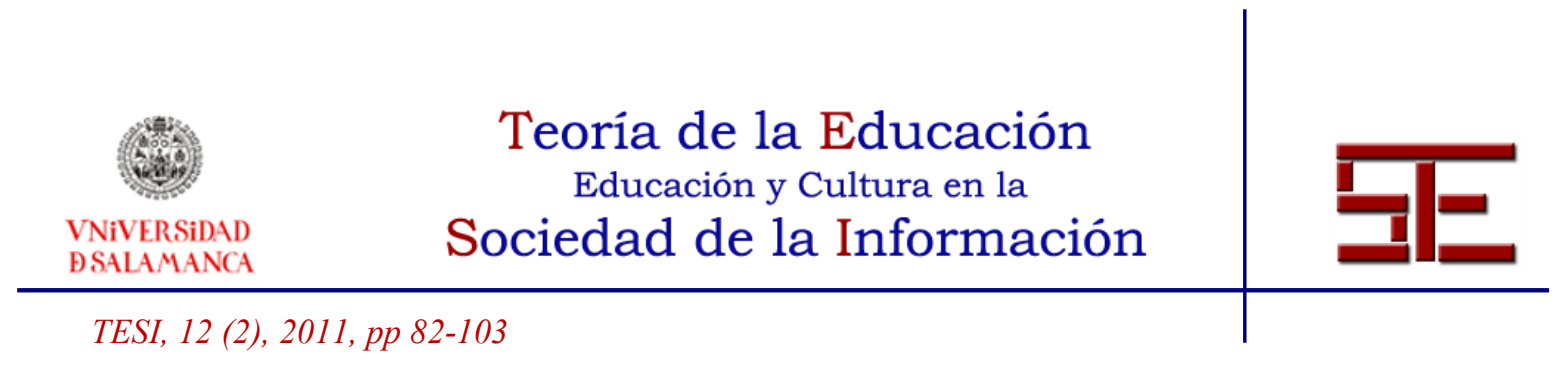

Atendiendo al rol de dichos personajes, de los 129 principales, sólo 24 eran femeninos $(18,60 \%)$. En cuanto a los personajes secundarios, de los 701 personajes totales de esta categoría, 239 son femeninos (34,09\%). Es de destacar la poca presencia de personajes femeninos entre los personajes principales de las películas de género deportivo, invisibilizando de esta manera una práctica cada vez más mayoritaria entre las mujeres de nuestra sociedad.

\begin{tabular}{|c|c|c|c|c|c|c|c|c|}
\cline { 2 - 9 } \multicolumn{1}{c|}{} & \multicolumn{2}{c|}{ PRINCIPALES } & \multicolumn{2}{c|}{ SECUNDARIOS/AS } & \multicolumn{4}{c|}{ TOTALES } \\
\cline { 2 - 9 } \multicolumn{1}{c|}{} & RECUENTO & $\%$ & RECUENTO & $\%$ & RECUENTO & $\%$ & MEDIA & DESV. TIP. \\
\hline GENERO & 129 & $100 \%$ & 701 & $100 \%$ & 830 & $100 \%$ & & \\
\hline Femenino & 24 & $18,60 \%$ & 241 & $34,38 \%$ & 265 & $32,05 \%$ & 1,78 & 2,08 \\
\hline
\end{tabular}

Figura 1. Distribución de roles femeninos.

Relativo a la edad de los personajes femeninos, los personajes principales son preferentemente adolescentes $(45,83 \%)$ y jóvenes $(41,67 \%)$, correspondiendo el resto a adultas (12,50\%). Con estos datos es imposible obviar que las chicas jóvenes tienen bastante peso como personajes secundarios (el 50,21\% de las mujeres con un papel secundario son jóvenes, por el $29,05 \%$ de adultas y el 13,28\% de adolescentes; el resto de valores son poco significativos).

La indumentaria mostrada por los personajes femeninos principales es mayoritariamente de vestir $(60,89 \%)$, estando en un segundo nivel, a buena distancia del primero, el referido a la indumentaria deportiva $(23,27 \%)$; el resto de categorías (ropa de gala, laboral, desnudez $\mathrm{u}$ otras) presentan porcentajes poco significativos. Las secundarias también responden a la misma distribución, aunque con una diferencia más acusada entre los dos primeros niveles, estando la ropa de vestir en un altísimo 74,47\% y la deportiva en un $8,60 \%$; a mucha distancia aparecen el resto de categorías. Este dato es de destacar dado que dentro de una trama ambientada en prácticas deportivas, lo lógico sería pensar que las prendas deportivas serían las más frecuentes.

Tanto en el caso de los personajes femeninos principales como en el de las secundarias, la indumentaria, independientemente de la tipología de la misma, presenta porcentajes similares de seducción (un tercio) y funcionalidad (dos tercios). Estos datos son interesantes pues indican que la indumentaria de las féminas tiene un cierto carácter seductor, aunque la temática propia de las películas analizadas abogaría por un carácter funcional, más apto para la práctica deportiva.

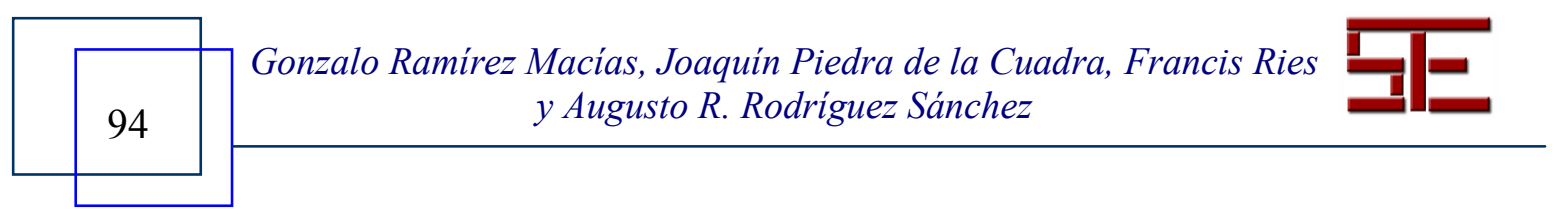




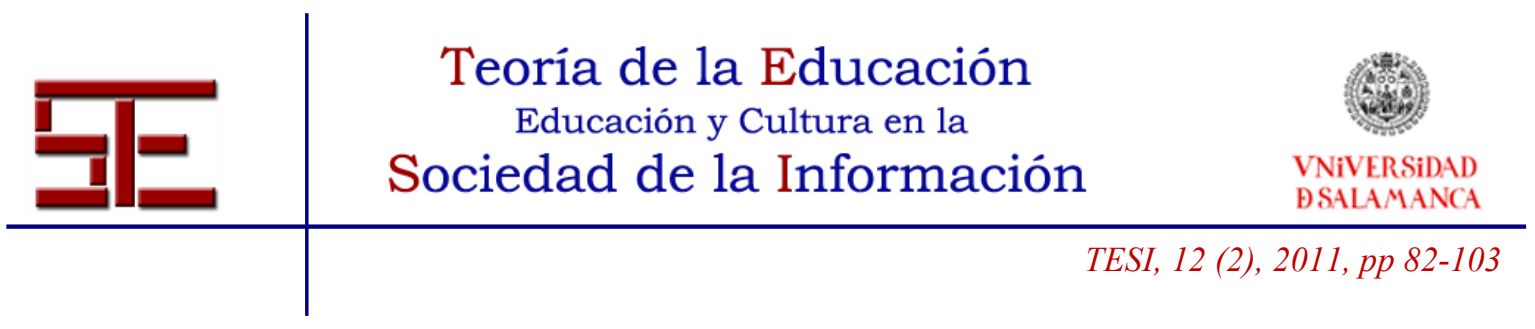

Este dato junto con el anterior de los tipos de indumentaria no hace más que afirmar lo diversos autores vienen afirmando (Messner, 2002), el uso del cuerpo de la mujer con el fin de atraer y seducir al hombre.

Para comprender el papel que las mujeres desempeñan en este tipo de tramas, es importante también analizar las cualidades mostradas por los personajes femeninos, datos que nos pueden dar una idea de qué cualidades, en su vertiente positiva o negativa, se asocian a los paradigmas femeninos ya sean buenos o malos, es decir, qué estereotipos son propios de modelos de mujeres ideales y cuales son propios de modelos femeninos perversos. Se destaca que las protagonistas principales se caracterizan positivamente y en este orden por el apasionamiento, la belleza estética, la valentía, la tenacidad y la rebeldía. En el polo opuesto, se hallan como características valoradas más negativamente la agresividad y la manipulación, seguidas de la competitividad, la belleza estética y la ternura. Llama la atención el carácter ambivalente de la belleza estética, la agresividad y la ternura; sin embargo no dan lugar a dudas en cuanto a su carácter negativo la manipulación y la competitividad.

Por su parte, las cualidades positivas de las féminas secundarias registran una mayor frecuencia de la ternura, seguida de la belleza estética y de la maternidad. Mientras, las cualidades consideradas de forma negativa expresan una distribución más uniforme, destacando la manipulación, la pasividad, la agresividad y la competitividad; manifestándose otras tantas de forma más reducida (sin inquietudes de superación, la fragilidad, la rebeldía, la tenacidad o la frialdad). Los datos de las cualidades asociadas a los personajes femeninos no hacen más que repetir y reproducir los estereotipos tradicionalmente asignados a las mujeres en la sociedad de la información en la que nos encontramos.

\section{5. - DISCUSIÓN.}

La investigación del presente estudio se centró en el análisis de los personajes femeninos de las películas de género deportivo de la primera década del siglo XXI, valorando si este tipo de películas reproduce los estereotipos y roles sociales que se imponen en la sociedad occidental con respecto al género femenino.

Los resultados evidencian que la imagen de la mujer en las películas de género deportivo estudiadas, responde a los siguientes caracteres: mujer joven con rol secundario, con cualidades de maternidad, belleza y ternura; siendo siempre

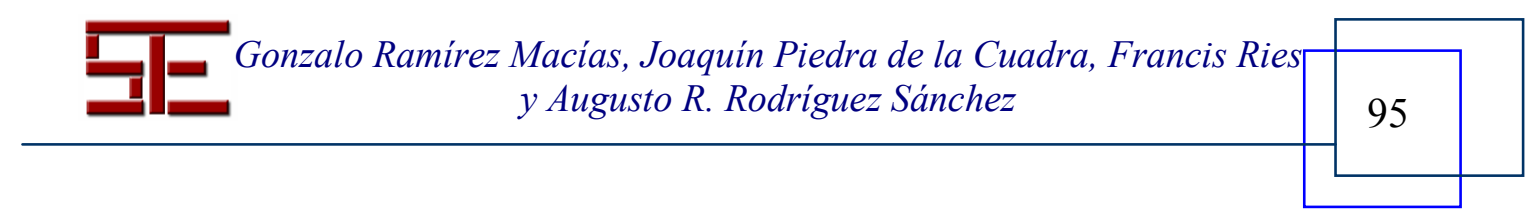




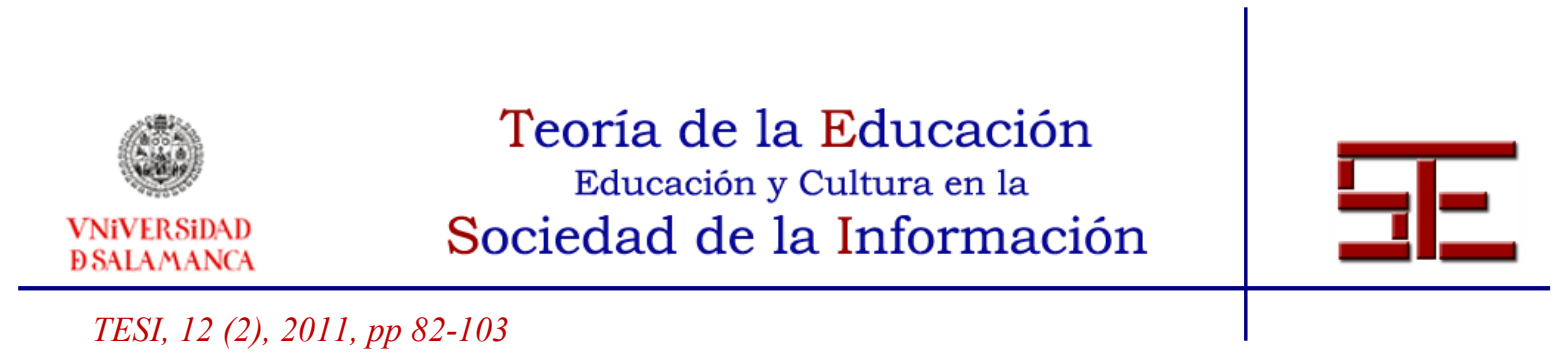

interpretados estos caracteres como positivos en una mujer. El cine endurece y legitima todo tipo de estereotipos sobre la mujer, representándola en ocasiones en papeles secundarios y tradicionales configurando así una imagen de la mujer anclada en el pasado. En otras ocasiones, cada vez más en el cine actual e impulsado por la incorporación de la mujer en labores de dirección cinematográfica, el rol de la mujer va tomando otra importancia y el cine presenta a la sociedad una visión crítica de la mujer dependiente o la de mujeres con clara independencia (Martínez-Salanova, 2005; Pfister, 2010).

Sin embargo, existen algunas películas como Million Dollar Baby, Bend It Like Beckham, Girlfight, y Offside en las que esta visión tradicional es trasgredida (Rowe, 2004), presentando un patrón de mujer no acorde con el "ideal" femenino (Williams, Lawrence \& Rowe, 1985). Esta posición parece ser compartida por la crítica cinematográfica, ya que muchos de los premios obtenidos por este género, han sido otorgados a estas películas. Estas mujeres transgresoras, como lo hicieron las primeras deportistas en el cine, son una esperanza para el cambio de percepción de la mujer en el deporte (Cashmore, 2000), cambios que también se observan actualmente en los medios de comunicación deportivos y pueden esperarse en el futuro debido a la propagación de los nuevos medios, sobre todo Internet (Pfister, 2010).

Los cánones de belleza exigidos a la mujer en la sociedad occidental se reflejan también en las películas analizadas en este trabajo. La necesidad de la mujer de mantenerse guapa, delgada y joven se materializa en la presencia mayoritaria de estos atributos en los personajes femeninos (Ventura, 2000). El cine y la televisión no sólo muestran que hay que pensar y valorar la estética personal; también dictan cómo hay que pensarla y valorarla. Como entidades de máxima competencia en cuestiones visuales y virtuales, los medios son paideía (Sartori, 1998: 36) y transmisores de las fórmulas para alcanzar una buena apariencia. "De la misma manera que en la cultura espiritualista la religión definía las recetas y las guías para salvar el alma, en la sociedad de las representaciones los medios son forjadores, exegetas y garantes de los cánones estéticos, y propagan las fórmulas y guías para preservar un físico deseable" (Martín, 2002: 6).

La edad de los personajes femeninos en las películas de género deportivo parecen concordar con la sociedad actual, apreciándose desde la adolescencia un descenso paulatino de la práctica deportiva de las mujeres conforme se avanza en la edad; estos datos coinciden con los obtenidos por estudios sobre el abandono de la

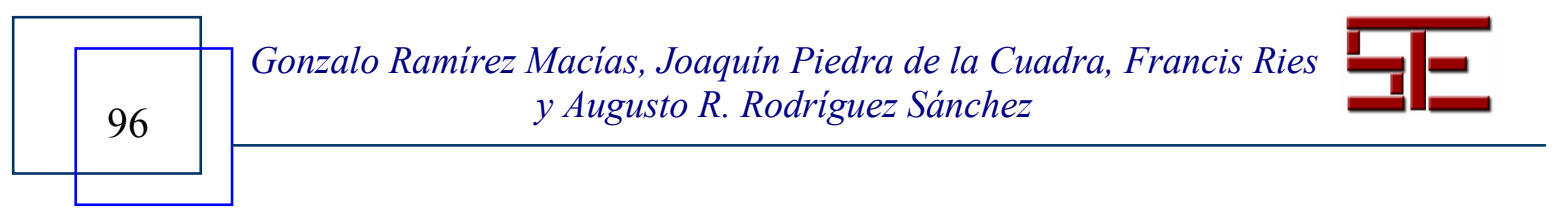




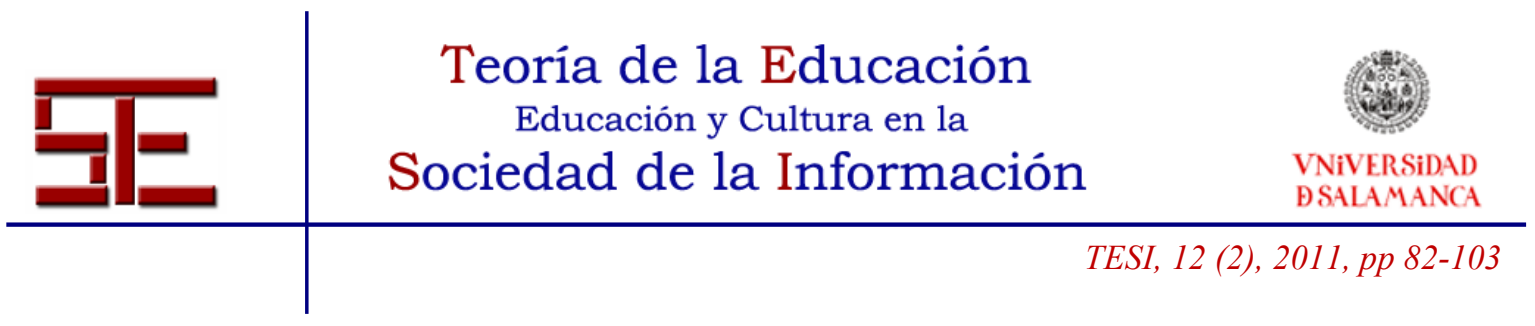

práctica deportiva (Instituto de la Mujer, 2006; Talbot, 1988; Brown, Frankel \& Fennell, 1991; Sarrazin, 2002).

Las cualidades asignadas a las mujeres en estas películas se corresponden con los estereotipos sexistas presentes en la sociedad patriarcal: maternal, tierna, estética, manipuladora, etc. son escasas las ocasiones en las que estos estereotipos no aparecen asociados a la mujer.

El argumento de las películas estudiadas gira en torno a la práctica de deportes tradicionalmente no adecuados al ideal femenino: el boxeo clasificado por Snyder y Spreitzer (1983, citados por Cashmore, 2000) como categóricamente inaceptable para la mujer y deportes como el fútbol americano o el fútbol 11 catalogados como generalmente inaceptables, son los que mayor presencia tiene en este género de películas (ver también Pfister, 2010). La práctica deportiva de las mujeres en estas películas se identifica con actividades coreográficas, en su mayor parte identificadas como cheerleaders, a la que se reduce en muchos casos la presencia y práctica femenina. Asumen, por tanto, un rol de apoyo a un personaje masculino o incluso premio para un exitoso deportista (Messner, 2002; Messner, Duncan y Cooky, 2003). Estos hechos no hacen más que redundar en la subordinación de la mujer como individuo inferior en las películas deportivas, tal como lo afirman en sus respectivos trabajos Duncan y Messner (1998), y Duncan y Hasbrook (2002).

Sin embargo, podemos subrayar que en las películas que tratan las actividades de riesgo y en la naturaleza hay una acentuada presencia de mujeres, ya que, según Messner (2002), Kennedy (2001) y White (2004), estos deportes se presentan como alternativas en las que la mujer cambia la hegemonía masculina de otros deportes.

De manera general, las características de los personajes femeninos en las películas deportivas hacen que se pueda catalogar a la mayoría de estos como "Cenicientas", mujeres pasivas que dan apoyo al varón protagonista. Sin embargo, existen algunos casos, como hemos podido comprobar, en los que se rompe este estereotipo presentando a personajes de la tipología "Heroína subversiva".

En el análisis de los personajes sin un papel destacado, que aparecen como figurantes, a través del "registro anecdótico", se aprecia el uso del cuerpo de la mujer como herramienta provocativa-sexual y con poca ropa (Messner, 2002; Pfister, 2010). Es lo que el sociólogo estadounidense Messner (2002) denomina Humorous

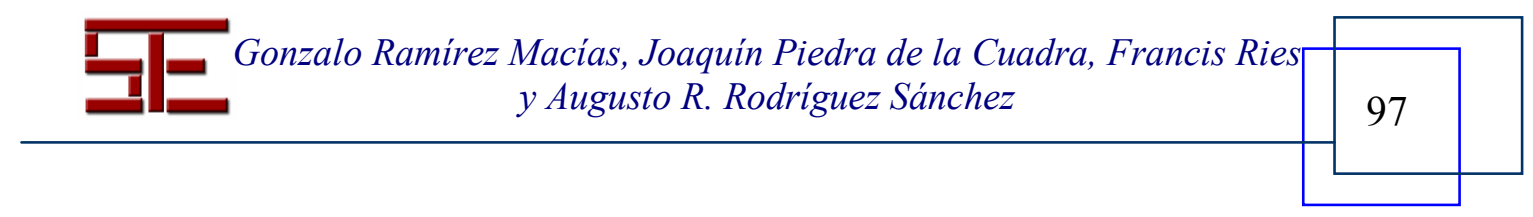




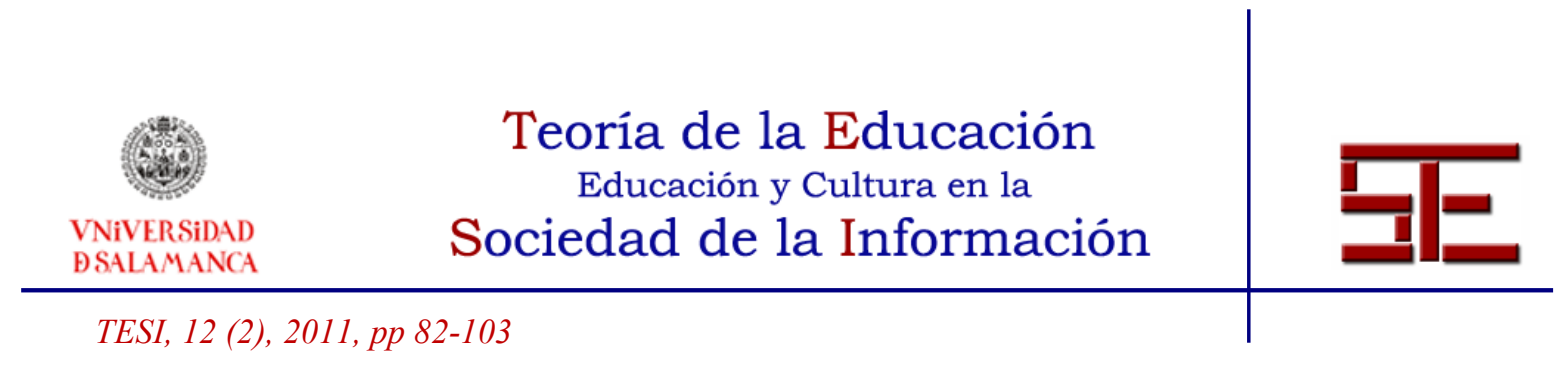

Sexualization como forma de discriminación de la mujer. Además hay que destacar otra forma de discriminación que se observa en este género de películas, la denominada discriminación Silence: La poca presencia de personajes principales en las películas lleva a la invisibilización de la imagen de la mujer como individuo deportivo, no dando ejemplos positivos a seguir para los espectadores y espectadoras.

\section{6.- CONCLUSIONES.}

Tras la revisión y análisis del presente estudio, ha de concluirse que la figura femenina distribuida por la industria cinematográfica moderna concuerda con un estereotipo de mujer ajustada al canon de belleza, habitualmente vestida con ropa seductora y cuyo rol oscila entre ser el objeto de deseo o la acompañante fiel, tierna y comprensiva de la figura masculina protagonista. Paralelamente, su participación en el contexto deportivo, común a la muestra, suele encajar en actividades coreográficas, habitualmente de apoyo o accesoria a la práctica deportiva central de la película (como es el caso del cheerleading).

La industria cinematográfica no deja de ser una herramienta difusora de contenidos y como toda herramienta, su bondad estriba en las intenciones de las personas que la promueven. Como toda industria, tiene una interdependencia de su éxito y calado social como variables para perpetuarse, siendo esta perspectiva mercantilizada la que evita arriesgar por modelos diferentes a los percibidos en la sociedad moderna. No se debe olvidar que entre el cine y la sociedad se forma una relación de vasos comunicantes. El cine "extirpa" sus contenidos de la realidad, los procesa usando sus reglas y reintegra estos contenidos a la realidad. Pero la industria del cine se guarda mucho de soliviantar a sus espectadores $\mathrm{y}$, por tanto, intentará no atentar contra las corrientes que estén de moda en la sociedad actual. Estará muy atento a lo que se "cuece" en la sociedad para adelantarse si es posible y dar una visión original o escandalosa para llenar las salas de cine. Se incorporará a la crítica, al análisis que la sociedad hace en cada momento, intentando visiones novedosas que en muchos casos tergiversan el verdadero problema, lo alejan de nosotros: "son cosas que pasan en el cine", porque la realidad que nos circunda la percibimos distinta.

En esta situación, el binomio "cine-sociedad" supone una relación simbiótica, donde uno se nutre de las actitudes percibidas y en el otro y viceversa. Salvo muy honrosas excepciones, el ambiente patriarcal imperante en la sociedad ha supuesto un catalizador idóneo para la perpetuación de dichos modelos en la industria

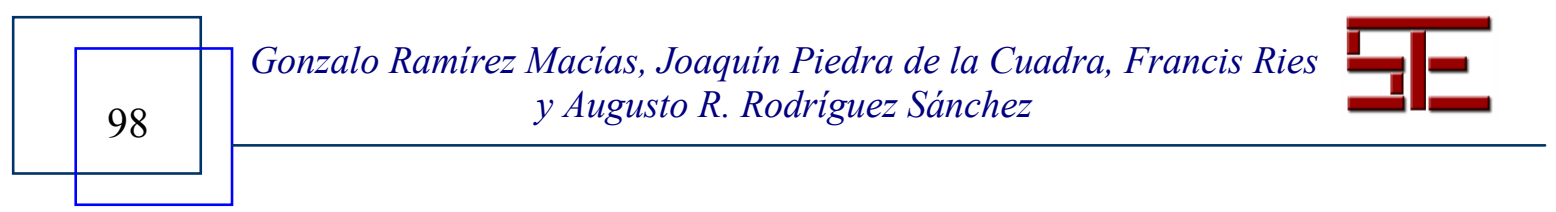




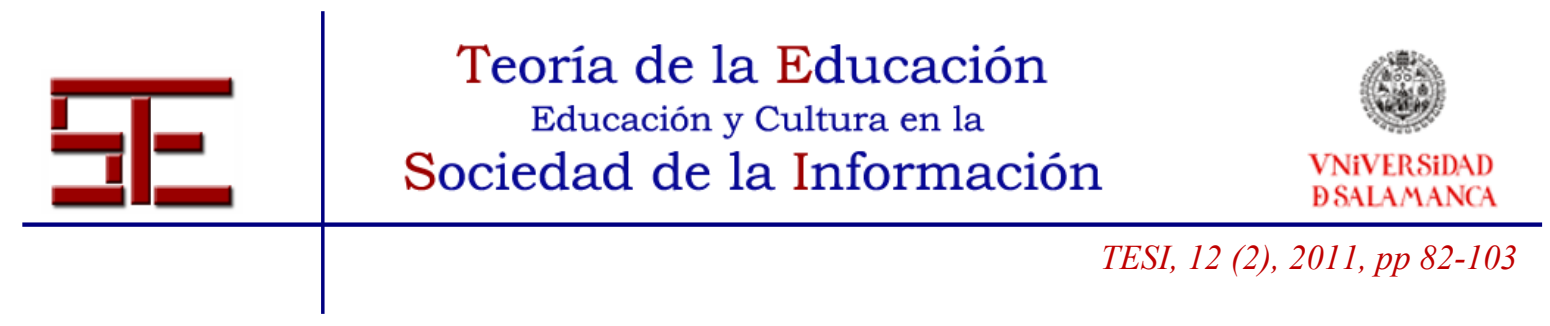

cinematográfica más comercial (que es el producto de mayor consumo, comparativamente con las producciones más independientes y transgresoras). Modelos en los que la mujer se ha constituido como "premio" en el hito vital del sempiterno protagonista masculino, como colofón final a los obstáculos superados en la historia o como acompañante necesaria en momentos vitales, pero siempre orientado a ensalzar la figura masculina (un rol que tiene también sus raíces en las producciones principescas infantiles).

El estereotipo de mujer puede parecer igualmente difícil de abandonar debido a que una alienación de la mujer sobre este rol que tradicionalmente se le asocia puede conducir a encasillarla en una actitud "masculinizante". Esta actitud refuerza la evidencia de la perspectiva poco arriesgada y educativa que en muchas ocasiones caracteriza a la industria del cine, además de mostrar que adoptar clichés estereotipados supone la obligación que salir de uno supone encasillarse en otro (el opuesto, en este caso).

Sobre este paradigma, las actuales política de educación en pos de la consolidación de la figura femenina están siendo de especial importancia sobre tres focos de atención: En primer lugar, supone la maduración social necesaria para contrastar de forma crítica los modelos planteados en los mass media, reduciendo de esta forma el impacto en la perpetuación de estereotipos que actualmente dan un tratamiento femenino como "objeto" en lugar de "sujeto". En segundo lugar, supone la incorporación de la figura femenina a la industria cinematográfica en roles directivos, por lo que sumado a las políticas de concienciación sobre la mujer, supondrán un cambio en la forma en que se diseñan y distribuyen los contenidos. En tercer lugar, el cambio de enfoque sobre la proliferación de estereotipos que hasta ahora se ha llevado a cabo supondrá el incentivo necesario para reforzar las políticas de igualdad imperantes en la sociedad moderna.

De este modo, un enfoque holístico de concienciación a todos los niveles sobre el binomio "sociedad-industria cinematográfica" no sólo permitiría seguir avanzando en dirección a la restitución de la integridad de la figura de la mujer con pleno derecho, sino que direccionaría el uso de una herramienta de difusión como es la industria del cine hacia motivos superiores, universales y ejemplarizantes para la sociedad que los estrictamente mercantiles.

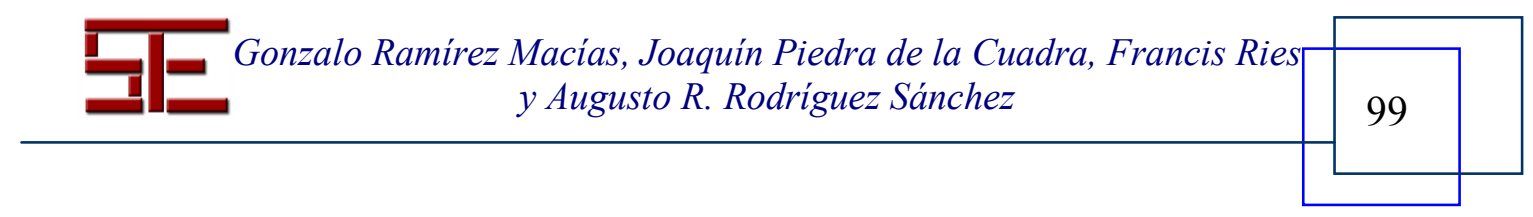




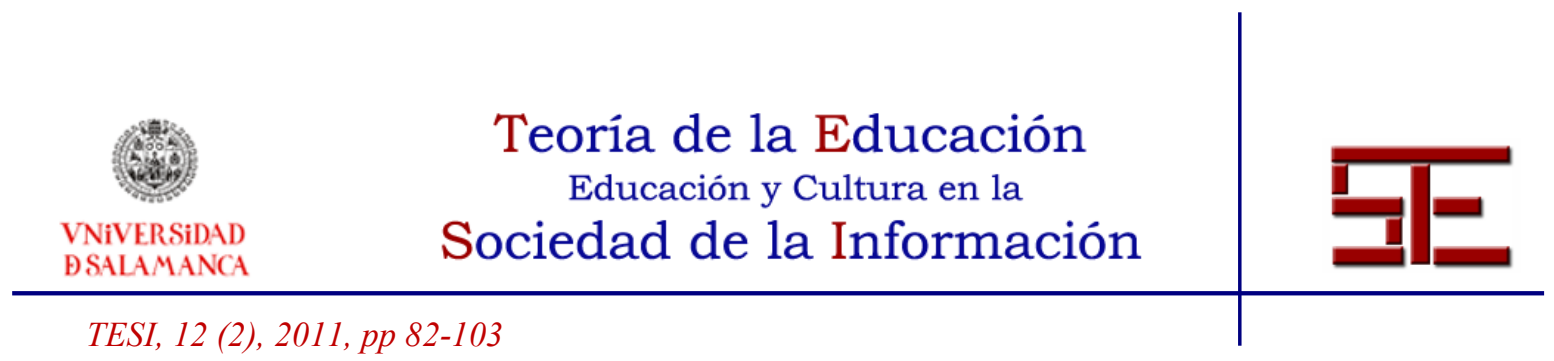

\section{7.- BIBLIOGRAFÍA.}

- Baker, A. (2006). Contesting identities. Sports in American film. Urbana: University of Illinois Press.

- Bandura, A. (1986). Social foundations of thought and action: A social cognitive theory. Englewood Cliffs: Prentice Hall.

- Barberá, E. (2004). Perspectiva socio-cognitiva: estereotipos y esquemas de género. In E. Barberá y I. Martínez (Comps.), Psicología y género (pp. 55-80). Madrid: Pearson Educación.

- Bardin, L. (1986). El análisis de contenido. Madrid: Akal.

- Bishop, R. (2003). Missing in action: feature coverage of women's sports in Sport Illustrated. Journal of Sport and Social Issues, 27 (2), 184-194.

- Bisquerra, R. (1989). Métodos de investigación educativa. Barcelona: CEAC.

- Blanco, E. y Naranjo, A. (2008). Imagen estereotipada y escaso protagonismo de la mujer en la prensa de referencia. En A. Gómez (Coord.), Mujeres, política y medios de comunicación. Homenaje a Clara Campoamor (pp. 171-180). Sevilla: Fundación Audiovisual de Andalucía.

- Blández, J., Fernández, E. y Sierra, M.A. (2007). Estereotipos de género, actividad física y escuela: La perspectiva del alumnado. Profesorado. Revista de currículum y formación del profesorado, 11 (2) Retrieved from http://www.ugr.es/ recfpro/ rev112ART5.pdf

- Bogdan, R. (2007). Qualitative research for education: an introduction to theory and methods. Boston: Allyn and Bacon, cop.

- Boyle, E., Millington, B. y Vertinsky, P. (2006). Representing the Female Pugilist: Narratives of Race, Gender, and Dis-ability in Million Dollar Baby. Sociology of Sport Journal, 23 (2), 99-116.

- Brown, B.A., Frankel, B.G. y Fennell, M. (1991). Happiness through leisure: The impact of type of leisure activity, age, gender and leisure satisfaction on psychological well-being. Journal of Applied Recreation Research, 16, 367-391.

- Cashmore, E. (2000). The secondbest sex. How women are devalued and diminished by sports. In E. Cashmore (ed.), Making sense of sports (pp. 163183). London: Routledge (3rd Edition).

- Caudwell, J. (2008). Girlfight: boxing women. Sport in Society, 11 (2/3), 227239.

- Clemente, M.D. (2007). Mujeres del Far West. Estereotipos femeninos en el cine del Oeste. Área Abierta, 17, 1-15.

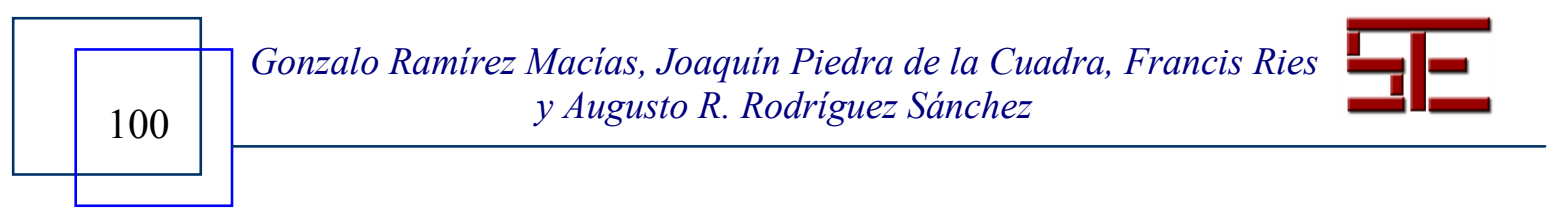




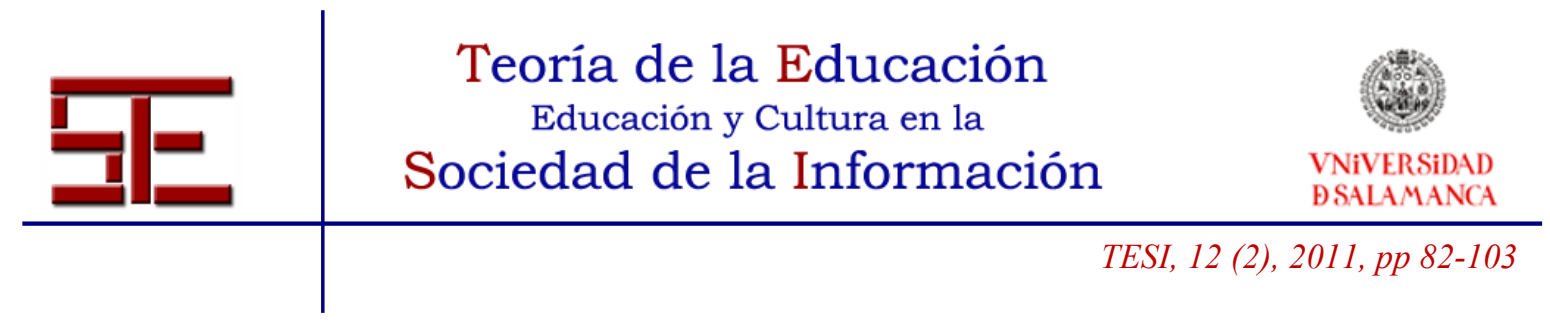

- Contreras, F. (2007). Perspectivas feministas en el conocimiento y la actividad mediática. En F. Loscertales y T. Nuñez (Coords.), La mirada de las mujeres en la sociedad de la información (pp. 17-60). Madrid: Siranda Editorial.

- Correa, R., Guzmán, Ma. y Aguaded, J. (2000). La mujer invisible. Una lectura disidente de los mensajes publicitarios. Huelva: Grupo Comunicar.

- Crawford, M. y Unger, R. (2004). Women and Gender. New York: Mc Graw Hill ( $4^{\mathrm{a} e d}$.).

- Duncan, M.C. y Hasbrook, C.A. (2002). Denial of power in televised women's sports. In S. Scraton y A. Flintoff (Eds.), Gender and Sport: a reader (pp. 8394). London: Routledge.

- Duncan, M.C. y Messner, M.A. (1998). The media image of sport and gender. En L.A. Wenner (Ed.). MediaSport (pp. 170-185). New York: Routledge.

- Garrett, R. (2004). Gendered bodies and physical identities. In J. Evans, B. Davies y J. Wright (Eds.), Body knowledge and control. Studies in the sociology of physical education and health (pp. 140-156). London: Routledge.

- Gilpatric, K. (2010). Violent Female Action Characters in Contemporary American Cinema. Sex Roles. Retrieved from http://www.springerlink.com/content/ j6923218724t7430/fulltext.pdf

- González, M. (2005). ¿Tienen sexo los contenidos de la Educación Física Escolar? Transmisión de estereotipos de sexo a través de los libros de texto en la etapa de secundaria. Revista Internacional de Medicina y Ciencias de la Actividad Física y el Deporte, 5(18), 77-88.

- Guarinos, V. (2007). Mujeres en proyección. La mujer en el cine. Teoría fílmica femenina. En F. Loscertales y T. Nuñez (Coords.), La mirada de las mujeres en la sociedad de la información (pp. 91-112). Madrid: Siranda Editorial.

- Guttman, A. (1996). The erotic in sports. New York: Columbia University Press.

- Hargreaves, J. (1994). Sporting females: critical issues in the history and sociology of women's sports. London: Routledge.

- Huggins, M. (2007). And now, something for the Ladies: representations of women's sport in cinema newsreels 1918-1939. Women's History Review, 16 (5), 681-700.

- Instituto de la mujer (2006). Actitudes y prácticas deportivas de las mujeres en España (1990-2005). Serie Estudios; 92. Editorial Madrid.

- Kennedy, E. (2001). She wants to be a sledgehammer? Tennis femininities in British Television. Journal of Sports and Social Issues, 25, 56-72.

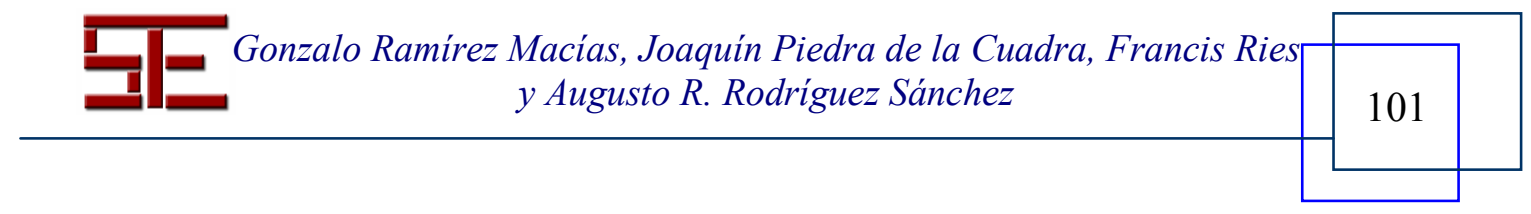




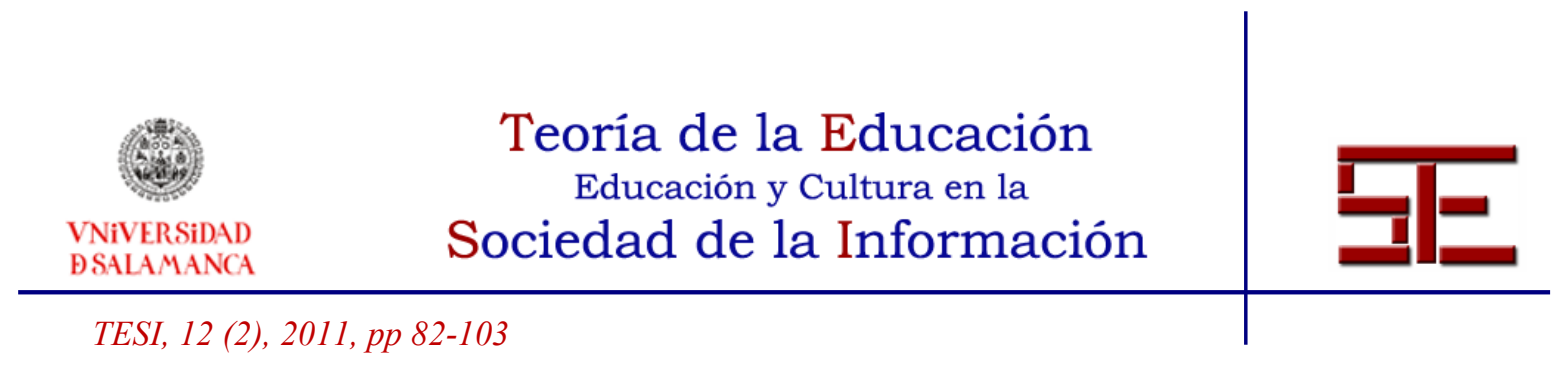

- Krippendorff, K. (1990). Metodología del análisis de contenido. Barcelona: Paidos Comunicación.

- López, C. (2005). Las imágenes fijas del cuerpo relacionadas con la actividad física y el deporte. Análisis de su uso en la publicidad de revistas. Memoria para optar al título de Doctor. Facultad de Ciencias de la Educación, Universidad de Vigo, Vigo, España.

- Loscertales, F. (2007). Medios basados en la imagen y medios basados en la palabra. En F. Loscertales y T. Nuñez (Coords.), La mirada de las mujeres en la sociedad de la información (pp. 61-70). Madrid: Siranda Editorial.

- Martín Llaguno, M. (2002). La tiranía de la apariencia en la sociedad de las representaciones. Revista Latina de Comunicación Social, 50. Extraído de: http://www.ull.es/publicaciones/latina/2002/latina50mayo/5005mllaguno.htm (15 de abril de 2011).

- Martínez-Salanova, E. (2005). El cine, otra ventana al mundo. Contrastes, revista cultural. Cultura sostenible, 40. Alicante.

- Mayring, P. (2000). Qualitative Content Analysis. Forum Qualitative Sozialforschung I Forum (On.line Journal) 1 (2). Retrieved from http://qualitative-research.net/fqs/

- Messner, M.A. (2002). Taking the field: women, men and sports. Minneapolis: University of Minnesota Press.

- Messner, M.A., Duncan, M.C., y Cooky, C. (2003) Silence, sports bras, and wrestling porn: Women in televised sports news and highlight shows. Journal of Sport and Social Issues, 27, 38-51.

- Neuendorf, K.A. (2002). The Content Analysis Guidebook. Thosand Oaks, CA: Sage Publications.

- Neuendorf, K.A., Gore, T.D., Dalessandro, A., Janstova, P. y Snyder-Suhy, S. (2010). Shaken and stirred: a content analysis of women's portrayals in James Bond films. Sex Roles. Retrieved from http://www.springerlink.com/content/ 2154051618834630/fulltext.pdf

- Pearson, D.W., Curtis, R.L., Haney, C.A. y Zhang, J.J. (2003). Sport Films. Social dimensions over time, 1930-1995. Journal of Sport \& Social Issues, 27 (2), 145-161.

- Pfister, G. (2010). Women in sport - gender relations and future perspectivas. Sport in Society, 13 (2), 234-248.

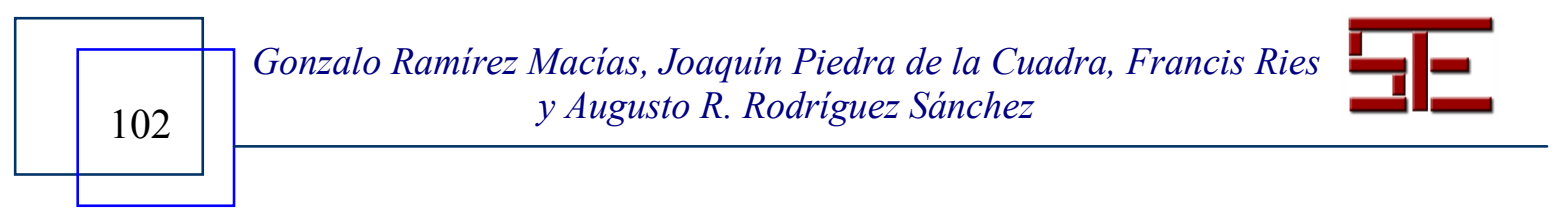




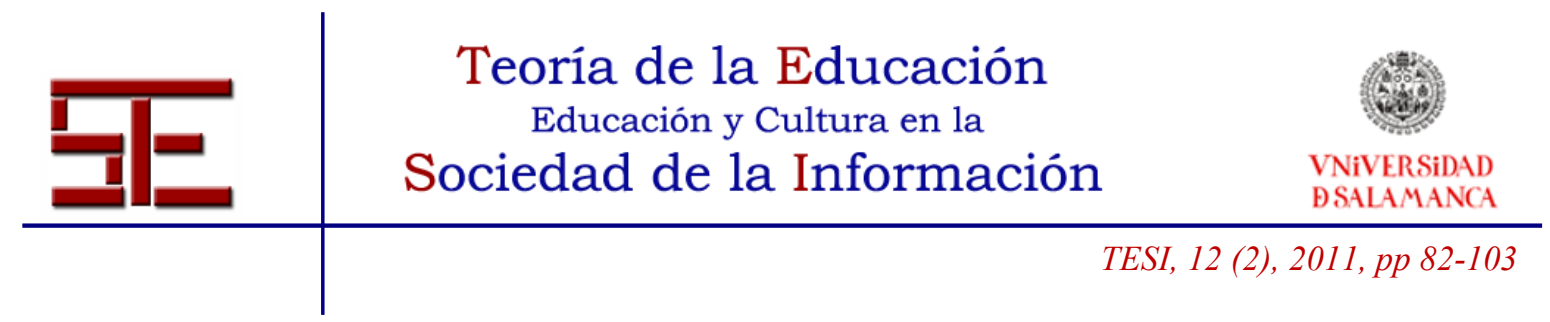

- Ramírez, G. (en prensa). Estereotipos corporales en las portadas de los videojuegos de género deportivo. Revista Internacional de Medicina y Ciencias de la Actividad Física y el Deporte.

- Rowe, D. (2004). Sport, Culture and the Media: The Unruly Trinity (2nd ed.), Maidenhead \& New York: Open University Press.

- Rowe, D. (2008). History of Sports and the Media. In W. Donsbach (Ed.), The International Encyclopedia of Communication (Volume X), (pp. 4798-4802). Malden, MA., Oxford, UK, Carlton, Vic: Blackwell,.

- Salvador, J.L. (2004). El deporte en occidente. Historia, cultura y política. Madrid: Cátedra.

- Sarrazin, P. (2002). L'abandon sportif: Causes et processus. Comunicación presentada en el IIlème Colloque Médico Technique du Ski Alpin. Octubre 2002.

- Sartori, G. (1998). Homo videns: la sociedad teledirigida. Madrid: Taurus.

- Schneider, A.J. (2000). On the definition of woman in the sport context. In T. Tannsjo y C.M. Tamburrini (Eds.). Values in Sport : Elitism, Nationalism, Gender Equality and the Scientific Manufacturing of Winners (pp. 123-138). London: Routledge.

- Scraton, S. (1992). Shaping up to womanhood. Gender and girls physical education. London: Open University Press.

- Stromquist, N. (2009). Las tecnologías de información y comunicación y las mujeres: ¿pueden las nuevas tecnologías desbaratar el género? TESI, 10 (3), 218230.

- Talbot, M. (1988). Understanding the relationships between women and sport. International Review for Sociology of Sport, 23, 31-42.

- Ventura, L. (2000). La tiranía de la belleza. La mujer ante los modelos estéticos. Barcelona: Plaza \& Janes.

- White, K. (2004). Discriminating airwaves. The Women's Sports Experience: A Newsletter for the Supporters of the Women's Sports Foundation 15 (4), 6-7.

- Williams, C.L., Lawrence, G. y Rowe, D. (1985). Women and sport: a lost ideal. Women's Studies International Forum, 8, 639-645.

\section{NOTAS}

${ }^{\mathrm{i}} \mathrm{http}: / /$ www.boxofficemojo.com

${ }^{i i} \mathrm{http}: / / \mathrm{www}$. filmaffinity.com/es

iii http://www.imdb.com

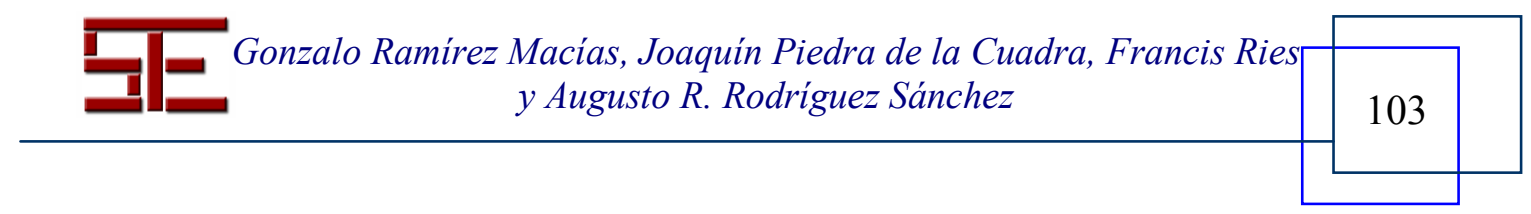


Teoria de la Educación

Educación y Cultura en la

VNiVERSiDAD

DSALAMANCA

Sociedad de la Información

TESI, 12 (2), 2011, pp 82-103

Para citar el presente artículo puede utilizar la siguiente referencia:

Ramírez Macias, G., Piedra de la Cuadra, J., Ries, F. y Rodríguez Sánchez, A. R. (2011). Estereotipos y roles sociales de la mujer en el cine deportivo, en Barrios Vicente, I. M. (Coord.) Mujeres y la sociedad de la Información. Revista Teoría de la Educación: Educación y Cultura en la Sociedad de la Información. Vol. 12, nº 2. Universidad de Salamanca, pp. 82-103 [Fecha de consulta: dd/mm/aaaa].

http://campus.usal.es/ revistas_trabajo/index.php/revistatesi/article/view/8274/8278

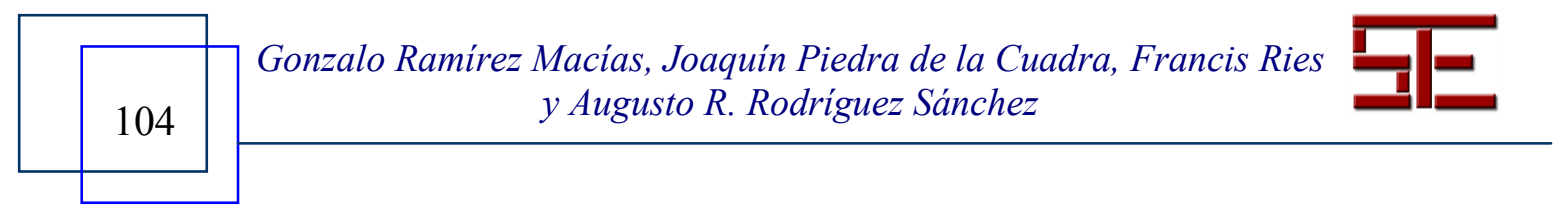

